CUAD. CONTAB. / BOGOTÁ, COLOMBIA, 16 (42): 625-660 / SEPTIEMBRE-DICIEMBRE 2015 / 625

\title{
Propuesta de un modelo para la prevención y gestión del riesgo de fraude interno por banca paralela en los bancos españoles*
}

doi:10.11144/Javeriana.cc16-42.pmpg

\section{José Antonio Arcenegui-Rodrigo}

Doctor en ciencias económicas y empresariales. Máster en gestión bancaria. Profesor del departamento de Finanzas, Universidad Loyola, Andalucía, España. Ha desarrollado su carrera profesional como auditor externo y ha ejercido responsabilidades como director financiero, interventor general, director de auditoría y control, así como director general en entidades financieras.

Correo electrónico: jaarcenegui@uloyola.es

\author{
José Manuel Martín-Lozano \\ Doctor en ciencias económicas y empresariales, Universi- \\ dad de Córdoba, España. Máster en dirección financiera \\ por ESIC-ETEA. Profesor titular de Ética y Finanzas, \\ Universidad Loyola, Andalucía, España. \\ Correo electrónico: jmmartin@uloyola.es
}

\begin{abstract}
Vicente Obrero-Castilla
Licenciado en Ciencias Económicas y Empresariales, Universidad Loyola, Andalucía. Responsable de auditoría interna en entidades financieras. Participante en las Comisiones Técnicas del Instituto de Auditores Internos en España.
\end{abstract}

Correo electrónico: vicente.obrero@cajasur.es

\footnotetext{
* Artículo de investigación científica realizado dentro de la línea de investigación de Ética y Finanzas en el departamento de Contabilidad y Finanzas de la Universidad Loyola Andalucía.
} 
Resumen El fraude interno por banca paralela se tipifica en España como la captación ilegal de dinero por parte de empleados bancarios o de terceros. Los casos de banca paralela tienen un importante impacto económico, legal y reputacional sobre las entidades financieras. Los principales problemas para gestionar y conocer este riesgo son la confidencialidad y la falta de información y de estadísticas con profundidad histórica suficiente.

Para solventar esta situación, este trabajo delimita el perfil del defraudador y las características temáticas del fraude. En función de estas características se proponen las técnicas y herramientas específicas para prevenir, detectar y mitigar este riesgo. Los mecanismos de prevención propuestos desarrollan un sistema de indicadores específicos y los correspondientes controles basados en la segregación de funciones. Igualmente, se plantean los requisitos para que los códigos éticos sean herramientas útiles en la lucha contra este fraude.

La propuesta del programa de trabajo que se realiza para la detección incluye el análisis de las distintas fases de la investigación forense. Adicionalmente, se proponen nuevas líneas de investigación basadas en el análisis de las nuevas bases de datos de las entidades financieras y un cambio de enfoque en el supervisor financiero que aumente la transparencia en la gestión de este riesgo.

Palabras clave entidades financieras; fraude interno; banca paralela; guía de prevención de riesgos; sistema financiero; gestión de entidades financieras; prácticas corruptas; auditoría

Códigos JEL M19, M42

\section{Model Proposal for Prevention and Management of Internal Fraud due to Parallel Banking in Spanish Banks}

\footnotetext{
Abstract In Spain, internal fraud due to parallel banking is defined as the illegal collection of funds by bank employees or third parties. Cases of parallel banking have an im-
}

portant impact on the reputation, economy, and legal areas of financial institutions. The main issues faced when managing and learning of this risk are confidentiality and the lack of information and statistics with a sufficient degree of historical depth.

To solve this situation, this work defines the profile of fraudster and the thematic characteristics of fraud. Based on these characteristics, we propose specific techniques and tools to prevent, detect, and mitigate this risk. The proposed prevention mechanism develops a specific indicator system -and its corresponding controls- based on function separation. Likewise, we set the requirements for ethics codes to be useful tools in the struggle against this kind of fraud.

The proposed work program to be carried out for detection includes the analysis of the different stages of forensic research. Additionally, we propose new research lines based on the analysis of the new databases of financial institutions and a change in the approach of financial supervisors which can lead to an increase in the transparency at the time of managing this risk.

Keywords financial institutions; internal fraud; parallel banking; risk-prevention guide; financial system; financial institution management; corrupt practices; auditing

\section{Proposta de modelo para a prevenção e gestão de risco de fraude interno por banca paralela nos bancos espanhóis}

Resumo A fraude interna por banca paralela é tipificado na Espanha como ilegal de dinheiro por parte de empregados bancários ou terceiros. Os casos de banca paralela têm importante impacto econômico, legal e reputacional sobre as entidades financeiras. Os principais problemas para conhecer e gerir o risco são a confidencialidade e falta de informação e estatísticas com profundidade histórica suficiente. Para findar esta situação, o trabalho delimita o perfil do defraudador e as caraterísticas temáticas da fraude. Em função destas características propõem-se técnicas e ferra- 
mentas específicas para prevenir, detectar e mitigar o risco. Propõem-se mecanismos de prevenção a desenvolver um sistema de indicadores específicos e controles correspondentes baseados em segregação de funções. Mesmo, levantam-se os requisitos para que os códigos éticos serem ferramentas uteis na luta contra este fraude.

A proposta do programa de trabalho para a detecção inclui análise das diferentes fases da pesquisa forense. Adicionalmente, propõem-se novas linhas de pesquisa baseadas na análise das novas bases de dados das instituições financeiras e uma mudança no enfoque do supervisor financeiro que aumente a transparência na gestão deste risco.

Palavras-chave instituições financeiras; fraude interna; banca paralela; guia de prevenção de risco; sistema financeiro; gestão de entidades financeiras; práticas corruptas; auditoria

\section{Introducción}

Un banco "es una institución cuyas operaciones habituales consisten en conceder préstamos y recibir depósitos del público" (Freixas \& Rochet, 1999, p. 1). Los bancos desarrollan su actividad mercantil en un entorno en el que la confianza entre cliente y empleado bancario es muy importante (Molina-Sánchez, 2014, p. 396). La materia prima con la que se prestan los servicios bancarios es el dinero. Estas circunstancias propician la aparición de casos de fraude y exponen a los bancos a la realización de estafas.

Los términos banca paralela, banca en la sombra o shadow banking se asocian generalmente a la existencia de entidades cuya actividad principal es la captación de recursos financieros del público, actuando fuera de la regulación de un país.
El tipo penal de la banca paralela está recogido en varias legislaciones nacionales (Panamá y Perú, entre otras) y se conceptualiza como la captación habitual de dinero por parte del público en forma de depósito sin estar debidamente autorizado para ello por el organismo estatal correspondiente.

Este artículo desarrolla una tipología de fraude interno que se produce en los bancos por el que un empleado, aprovechando su posición, realiza transacciones "paralelas" a las establecidas en los procedimientos de la entidad. La operación de banca paralela está reconocida por el Tribunal Supremo del Reino de España. Ese Tribunal conceptualiza este tipo de fraude como aquel en el que participa un empleado de banca y consiste en el desvío de fondos de clientes para préstamos a quienes tienen dificultades para obtener crédito regularmente ya sean relacionados o no con el propio empleado.

Por tanto, en el fraude interno por banca paralela (en adelante, fraude de banca paralela), normalmente un empleado realiza la actividad bancaria pero al margen del banco, sin que quede registro de ella en la contabilidad de la institución financiera y dando apariencia de legalidad a esta operación, al manipular los registros y la documentación.

Según las distintas clasificaciones del fraude (Bancoldex, 2015, p. 6; IAI, 2015, p. 22), la comisión de un delito de banca paralela por parte de un empleado de una entidad financiera normalmente implica la realización de varios delitos.

La colaboración y la realización de delitos y actos desleales por parte de los empleados del sector bancario provocan importantes pérdidas 
anuales en los bancos para los que trabajan y en sus clientes, con independencia del tamaño de las entidades bancarias implicadas o de los países donde ocurren.

A pesar de la falta de estadísticas de fraude que recojan datos históricos, como indican $\mathrm{Mi}$ chael Levi y Russell G. Smith (2011), hay una estrecha relación entre fraude y crisis económica. Las causas son evidentes (PwC, 2009, pp. 4-5): “cuando la supervivencia económica está en juego (ya sea de la organización o del individuo), la línea que separa el comportamiento aceptable del inaceptable puede volverse borrosa para algunos". Precisamente por esto, "las condiciones econó- micas actuales son una oportunidad para realizar acciones fraudulentas" y la recesión económica global es tal que los tres factores que originan el fraude -incentivo/presión, oportunidad y racionalización-están presentes como nunca antes.

En el caso de España, la situación macroeconómica no ha favorecido la mitigación de este tipo de fraude bancario. Desde el inicio de la crisis en 2007-2008, las elevadas tasas de desempleo entre los clientes, la reducción del crédito a empresas y familias, la reducción de la renta media de los hogares y el aumento de la población en riesgo de exclusión social, entre otros factores, favorecen la realización de actuaciones irregulares.

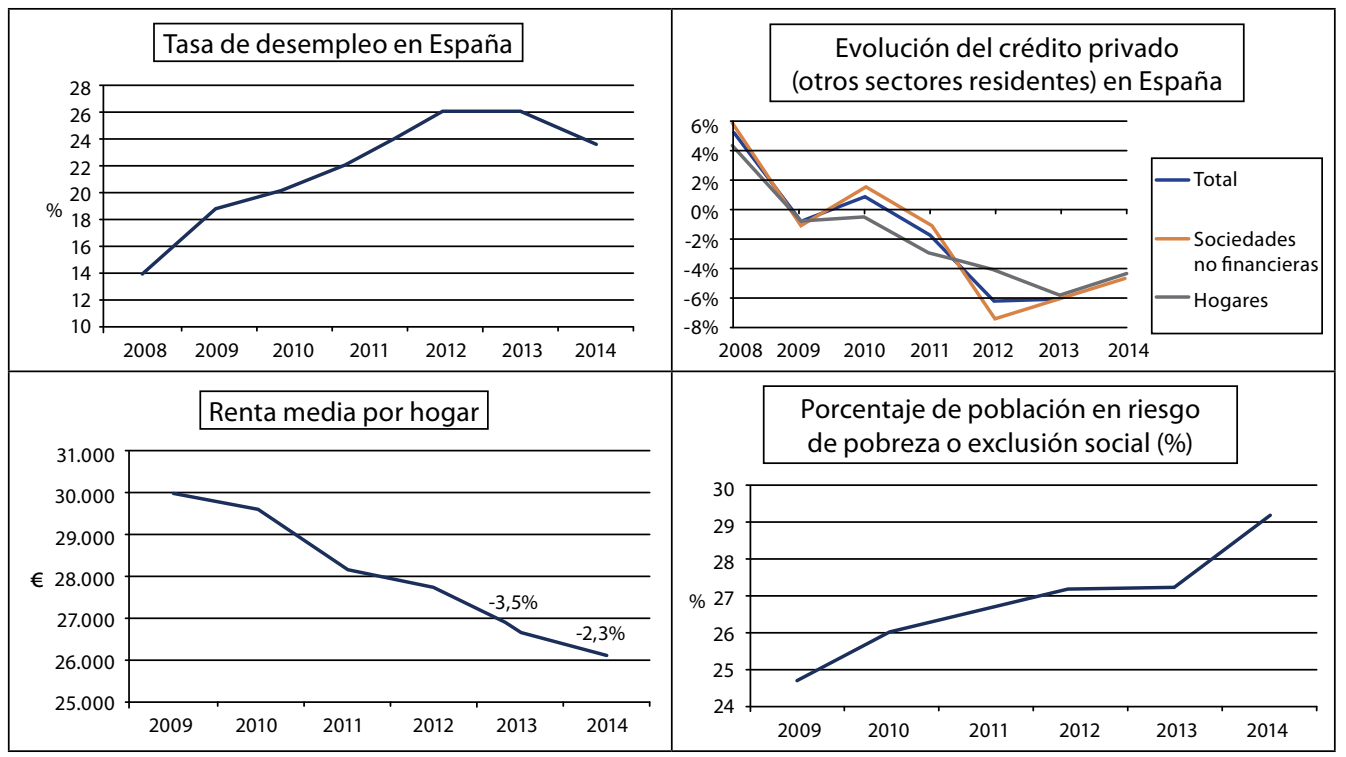

Gráfico 1

Datos macroeconómicos de España durante la crisis

Fuente: Instituto Nacional de Estadística (INE), Banco de España (2015a, p. 58), elaboración propia

Adicionalmente, hay que considerar la débil situación de las entidades financieras españolas, que desde el inicio de la actual crisis financiera han pasado por un proceso de concentración y un rescate del Banco Central Europeo, BCE. En este contexto, hay que valorar como factores de riesgo la precariedad del empleo bancario, el endeudamiento y las condiciones de vida de los 
empleados bancarios pues constituyen elementos que favorecen la realización y el descubrimiento de fraudes, que consiste en las señales de alerta típicas para los auditores internos que encuentran indicios de conductas fraudulentas.

Como matiza Louis Francis (2010), en las crisis económicas, los legisladores, reguladores y la mayoría de los gestores trabajan por evitar las quiebras de los bancos, no en la lucha contra el fraude. La mayoría de los esquemas PonziMadoff $^{1}$ se inician en épocas de bonanza, pero se ponen en evidencia en las crisis.
Uno de los factores que dificultan el estudio y lucha contra las bancas paralelas es la confidencialidad que rodea este tipo de fraude: las entidades financieras no suelen hacer públicos los casos que sufren, dado que su negocio se basa en su reputación y en la confianza de sus clientes.

Este trabajo tiene como objetivo describir las características del fraude por banca paralela, el perfil del defraudador, los colaboradores externos a la entidad bancaria y los defraudados. Así mismo, propone una guía para prevenir y mitigar este riesgo y para realizar una investigación forense

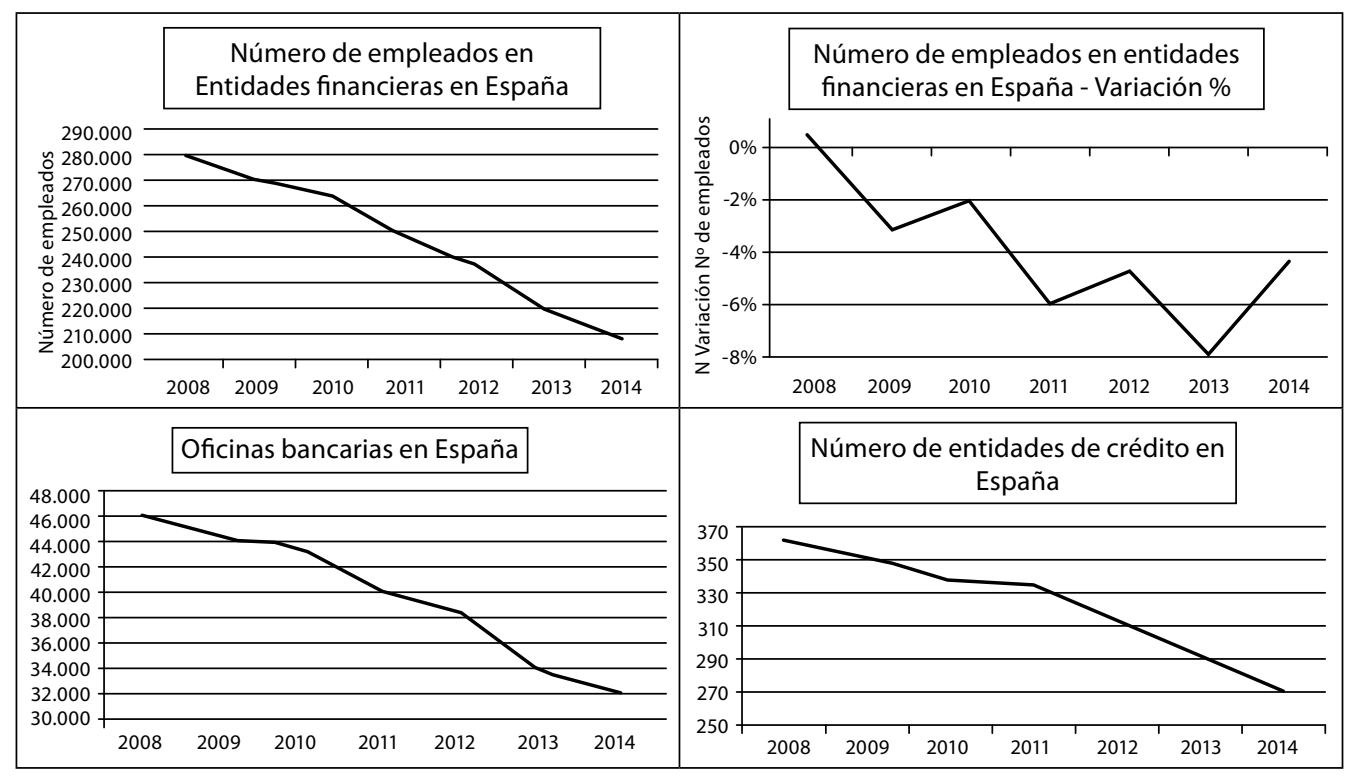

Gráfico 2

Situación del sector financiero español durante la crisis Fuente: Banco de España (2015b), elaboración propia

1 Estos esquemas de estafa ofrecen a los inversionistas pagos de rendimientos superiores a los del mercado, pues no los pagan con beneficios reales sino con las aportaciones de nuevos inversores. Estos fraudes necesitan constantemente la aparición de nuevos inversionistas para que con el nuevo capital aportado se remunere a los inversores anteriores. Por este motivo se les considera como típicas estafas piramidales. Esta estafa debe su nombre a Carlo Ponzi y Bernard Madoff.

completa, hasta la generación del informe final para la adopción de medidas laborales, jurídicas o contables, cuando el fraude ya ha ocurrido.

En el siguiente apartado se describirán las características de la banca paralela. En el apartado tres, se catalogan y analizan los perfiles de los participantes en el fraude. En el apartado 
cuatro, se propone la guía para la prevención y mitigación del riesgo de banca paralela en las entidades financieras y se reflexiona sobre la eficacia de los códigos éticos como herramienta de prevención del riesgo; mientras en el apartado cinco se propone un programa de trabajo específico para abordar un fraude de estas características. Finalmente y a modo de conclusión, se resumen los aspectos más significativos y las dificultades que rodean la prevención y la gestión de las bancas paralelas, propuestas para las entidades financieras y las autoridades, y las futuras líneas de investigación para conocer mejor este riesgo y mitigarlo adecuadamente.

\section{Características del fraude por banca paralela}

Como indica Julio Fernández-Sanguino Fernández (2002) en las instituciones financieras "se pueden desarrollar los mismos actos indebidos que en cualquier otro tipo de empresas; ahora bien, las características propias de la actividad bancaria, por la diversidad y exclusividad de sus operaciones y los numerosos riesgos existentes, hacen que en este sector se puedan producir más fraudes que en otras empresas y aparezcan, también, fraudes específicos que únicamente se producen en este tipo de entidades". Uno de los fraudes que se producen casi exclusivamente en las instituciones financieras es el fraude de banca paralela.

La banca paralela es un fraude interno típico de las instituciones financieras debido a que sus operaciones ofrecen una oportunidad más fácil de comisión al defraudador. La banca paralela es un fraude y, conforme a la SAS 99 (AICPA, 2002), es un acto intencionado del que resulta una manifestación errónea en los estados financieros.

\section{a. El problema de la confidencialidad} Para combatir eficazmente cualquier tipo de fraude se deben conocer sus características esenciales. La primera dificultad para conocer el fraude por banca paralela es la confidencialidad que rodea este fraude, durante su investigación (lo cual es necesario) pero también tras su conclusión. El temor a la pérdida de confianza de la clientela, cuando el fraude se conozca, provoca su ocultación.

En la actualidad, no hay estadísticas, ni públicas ni privadas, con profundidad histórica suficiente. La única fuente de información procede de los medios de comunicación cuando se producen filtraciones a la prensa. La opacidad ante los casos de bancas paralelas provoca el efecto contrario al perseguido cuando se hace público el fraude. Es razonable pensar que a mayor transparencia informativa mejor será la percepción de los stakeholders sobre su empresa, lo que probablemente redundará en una mejor imagen de la organización (Godfrey, Merrill \& Hansen, 2009). No obstante, como concluyen María del Pilar Rodríguez y Andrés Felipe Díaz (2004), resulta prioritario elevar aún más las exigencias informativas de las instituciones financieras en general, lo que repercutiría positivamente en un aumento del nivel de confianza de la sociedad.

La tabla 1 muestra, a modo de ejemplo, casos de banca paralela aparecidos en los medios de comunicación y ocurridos en España con la información más relevante hecha pública. Es significativa la repetición de los elementos esenciales de fraude que se analizarán con posterioridad. 


\begin{tabular}{|c|c|c|c|}
\hline Caso & Descripción del caso & Cuantificación & $\begin{array}{c}\text { Clientes afectados } \\
\text { y duración }\end{array}$ \\
\hline 1 & $\begin{array}{l}\text { Captación de inversores con la promesa de hasta un } 100 \% \text { de } \\
\text { interés al mes en inversiones simuladas en paraísos fiscales. }\end{array}$ & 5,4 millones de $€$ & 100 afectados \\
\hline 2 & $\begin{array}{l}\text { El dinero de los clientes se invertía en fondos de inversión } \\
\text { arriesgados en lugar de en depósitos a plazo fijo. }\end{array}$ & 0,8 millones de $€$ & 59 afectados \\
\hline 3 & $\begin{array}{l}\text { Venta de participaciones preferentes entre clientes, } \\
\text { sin estar estos conscientes del producto adquirido. } \\
\text { Apertura de préstamos a clientes sin su autorización ni su } \\
\text { conocimiento. }\end{array}$ & 2 millones de $€$ & n.d. \\
\hline 4 & $\begin{array}{l}\text { Se sacaba dinero de las cuentas de los clientes, con firma } \\
\text { falsificada o sin firmar. Falsificación de libretas bancarias } \\
\text { con saldos de imposiciones a plazo fijo y otros productos } \\
\text { de inversión que los clientes creían tener contratados, para } \\
\text { los que se ofrecía un porcentaje de beneficios mayor al de } \\
\text { mercado, en hasta el } 10 \% \text {. }\end{array}$ & 2,4 millones de $€$ & $\begin{array}{l}\text { Duración del fraude: } 23 \\
\text { años }\end{array}$ \\
\hline 5 & $\begin{array}{l}\text { Captación de clientes mediante falsas inversiones en } \\
\text { divisas. }\end{array}$ & 0,5 millones de $€$ & n.d. \\
\hline 6 & $\begin{array}{l}\text { Realización de inversiones inmobiliarias con dinero } \\
\text { extraído de las cuentas de los clientes. }\end{array}$ & 2,5 millones de $€$ & $\begin{array}{l}20 \text { afectados. Duración del } \\
\text { fraude: } 10 \text { años }\end{array}$ \\
\hline 7 & $\begin{array}{l}\text { Simulación de operaciones de clientes, la mayoría en } \\
\text { compra de deuda pública, y apropiación de dinero. }\end{array}$ & 1,7 millones de $€$ & 30 afectados \\
\hline 8 & $\begin{array}{l}\text { Realización de inversiones con el dinero de los clientes en } \\
\text { empresas, viviendas y otros proyectos de inversión para } \\
\text { quedarse con los beneficios, al tiempo que facilitaban } \\
\text { préstamos personales con la intención de apropiarse de los } \\
\text { intereses generados por los mismos. }\end{array}$ & 6 millones de $€$ & $\begin{array}{l}19 \text { detenidos y } 300 \\
\text { afectados }\end{array}$ \\
\hline 9 & $\begin{array}{l}\text { Falsificación de la documentación entregada a los clientes } \\
\text { con inexistentes fondos de inversión y planes de pensiones, } \\
\text { principalmente. }\end{array}$ & 1,2 millones de $€$ & 40 afectados \\
\hline 10 & $\begin{array}{l}\text { Realización de traspasos de dinero sin el consentimiento } \\
\text { de los clientes. Con el dinero captado, se realizaron } \\
\text { inversiones en bolsa y otras operaciones financieras al } \\
\text { margen del banco. }\end{array}$ & 0,4 millones de $€$ & 23 afectados \\
\hline 11 & $\begin{array}{l}\text { Captación de inversores a los que les ofrecían elevados } \\
\text { tipos de interés y no pagar impuestos. Entregaban a } \\
\text { clientes libretas no mecanizadas y emitían cheques } \\
\text { robados del banco para el pago de intereses. }\end{array}$ & 2,5 millones de $€$ & 16 afectados \\
\hline 12 & $\begin{array}{l}\text { Permitían el pago de cheques sin fondos. Fueron } \\
\text { condenados } 14 \text { clientes. }\end{array}$ & 1,7 millones de $€$ & n.d. \\
\hline 13 & n.d. & 6 millones de $€$ & n.d. \\
\hline 14 & $\begin{array}{l}\text { Realización de inversiones fraudulentas a cinco años de } \\
\text { plazo, retribuidas con intereses entre el } 6,75 \text { y el } 11 \% \text {, muy } \\
\text { superiores al mercado. }\end{array}$ & 2,8 millones de $€$ & 2 afectados \\
\hline 15 & $\begin{array}{l}\text { Ofrecimiento de inversiones con elevados intereses y } \\
\text { opacidad fiscal. El defraudador se apropiaba del dinero } \\
\text { el día en que se lo entregaban pues no lo anotaba la } \\
\text { contabilidad del banco. En otras ocasiones, lo retiraba de } \\
\text { las cuentas de los perjudicados imitando su firma. }\end{array}$ & 0,7 millones de $€$ & 16 afectados \\
\hline 16 & $\begin{array}{l}\text { Captación de inversiones entre los clientes de la sucursal } \\
\text { pagando intereses muy superiores a los de mercado. }\end{array}$ & 36 millones de $€$ & 300 afectados \\
\hline
\end{tabular}

Tabla 1

Ejemplos de casos de fraude por banca paralela en España publicados en los medios de comunicación

n.d.: no disponible

Fuente: elaboración propia 


\section{b. Características definitorias del fraude interno por banca paralela}

La banca paralela se suele tipificar como la captación ilegal de dinero por parte de empleados bancarios o de terceros en forma de depósitos u otras fórmulas de inversión sin estar debidamente registrados por la entidad correspondiente o la autoridad competente en cada país.

En la clasificación de Nicolás Darío Ramírez-Moncada (2009, p. 294), la banca paralela sería catalogable como un fraude interno en el que los empleados "se ganan la confianza de los clientes de la oficina, recibiendo de estos dineros que no son abonados a las obligaciones", o en las cuentas que el cliente tiene. Es decir, empleados con amplios perfiles de acceso manipulan la información del sistema y la confianza que tienen de sus compañeros de trabajo para apoderarse de depósitos de los clientes.

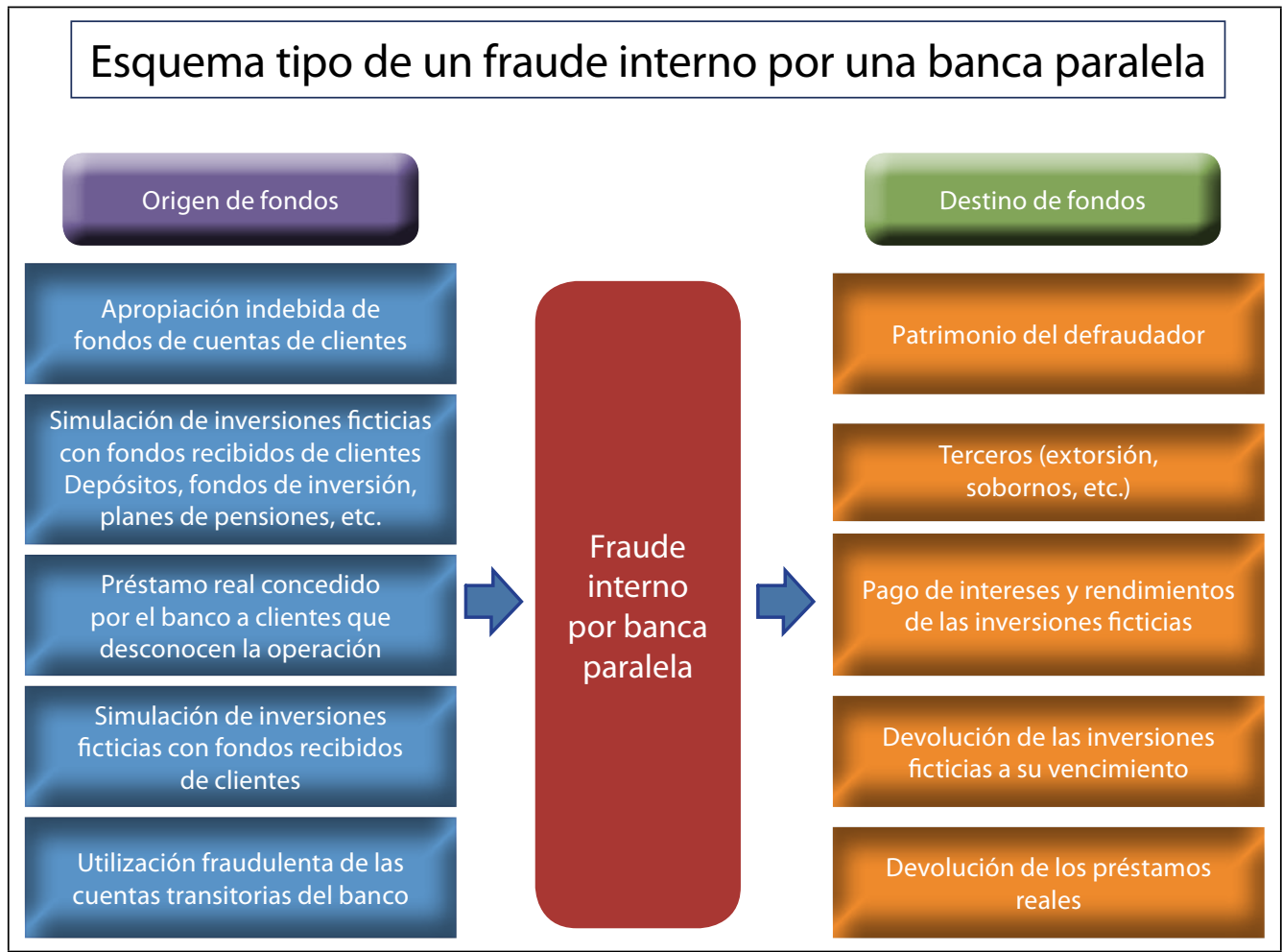

Gráfico 3

Esquema tipo de un fraude interno por banca paralela

Fuente: elaboración propia

En el gráfico 3 se muestran los principales orígenes y aplicación de fondos en una banca paralela. Esta tipología de fraude, coheren- temente con la información de la tabla 1, se enmarca entre los riesgos con gran impacto económico y reputacional, y una probabilidad de 
ocurrencia baja en comparación con fraudes menores y repetitivos como los fraudes con tarjetas o cajeros automáticos. A continuación, se describen las principales características del mismo:

- Este fraude es progresivo e incremental; como indican Richard H. Girgenti y Timothy P. Hedley (2013, p. 5), comienza con pequeñas cantidades sustraídas para probar la eficacia de los controles y se va incrementando en frecuencia e importes de las operaciones irregulares.

- Uso del procedimiento del lapping o solapamiento, que como describen Richard $\mathrm{H}$. Girgenti y Timothy P. Hedley consiste en atribuir ingresos de una cuenta en otra.

- Por ejemplo, el empleado bancario recibe unos fondos de un cliente para constituir un contrato de imposición a plazo. En lugar de abrir la cuenta en el banco, el empleado desleal se apropia de los fondos y le entrega al cliente documentación falsificada sobre la operación que acaba de realizar.

- El solapamiento natural comienza cuando llega el vencimiento de los fondos que el cliente entregó. Entonces, el empleado desleal necesita devolver el efectivo sustraído y la manera más sencilla es repetir la operación con otro cliente, pues destina parte de los fondos sustraídos en esta segunda operación a devolver el importe defraudado en la primera operación y el resto vuelve a apropiárselo.

- Es normal que el empleado defraudador se vea obligado a simular extractos bancarios cuando el cliente los solicite, al final de cada año o trimestre, incluso cuando el cliente deba presentar sus declaraciones fiscales.

- El procedimiento (Girgenti \& Hedley, 2013, p. 7) "puede exigir mucho tiempo y requiere un nivel elevado de mantenimiento. A menudo estos fraudes comienzan a pequeña escala, y los defraudadores suelen pensar que restituirán todas las sumas hurtadas en algún momento. A medida que el tamaño de los fondos malversados aumenta, o que se incrementa la frecuencia de los actos de malversación, cada vez es más difícil enmascarar o disimular el agujero del déficit, y se evapora la ficción de que el defraudador repondrá los fondos robados. Es frecuente que los empleados lleven un conjunto de anotaciones contables separadas para no perder la pista de las estratagemas que deben llevar a cabo con el fin de salvaguardar el equilibrio del engaño. No es inusual que los empleados involucrados en este tipo de estratagema se queden a trabajar hasta muy tarde, que rara vez se tomen vacaciones, y que sean maniáticos en cuanto a conservar el control y el secreto de sus áreas de la empresa. A menudo, solo se descubren estos fraudes cuando alguna incidencia no prevista ni planificada obliga al empleado a dejar por un tiempo su puesto de trabajo, y en su ausencia, otro empleado u otras terceras personas ocupan su lugar para hacerse cargo de sus funciones o revisarlas".

Un análisis de la tipología de fraude desde el marco del triángulo del fraude (Cressey, 1961) ofrece el resto de sus atributos específicos: 
- El motivo de su comisión (incentivo o presión) más habitual está en factores externos a la entidad financiera, como el prestigio personal, el trato de favor a terceros, la participación en negocios con conflicto de interés, etc. Igualmente, el fraude puede realizarse para ocultar factores internos negativos relacionados con la medición del desempeño laboral ${ }^{2}$.

- En cuanto a la posibilidad de realizar este tipo de fraude de banca paralela (oportunidad), es necesario que se den en el empleado una serie de características que le permitan desarrollarla y que se exponen en el siguiente apartado. No obstante, la oportunidad no solo surge por las habilidades o características del defraudador. Una deficiente identificación de riesgos y/o una pobre vigilancia de las operaciones y personas es asimismo una de las principales causas en la comisión de cualquier tipo de fraude (COSO, 2013).

- Por último, la racionalización que justifica este tipo de comportamientos es difícil de identificar, ya que suele pertenecer al ámbito interno del defraudador. Como explica Iván Eduardo Galvis-Castañeda (2008, p. 466), la psiquiatría y la psicología han comenzado a realizar interesantes aportaciones al campo de delito económico.

Para desarrollar una banca paralela es necesario realizar varios tipos de fraudes a la vez.

2 Por ejemplo, situaciones irregulares en la sucursal bancaria: morosidad por operaciones crediticias con mal criterio de concesión, faltante de efectivo por error operativo o por disposición ilegal del mismo, etc. El motivo de la banca paralela no suele ser la consecución de volúmenes de negocio dentro de la organización, ya que la propia operatoria de la banca paralela va en contra de este fin.
Un análisis que utiliza el modelo del árbol de fraude (IAI, 2015, p. 22) pone de manifiesto esta situación:

1. La estafa y la apropiación indebida de activos pueden ser un fin, en sí mismos, o un medio para la comisión del fraude de banca paralela. Cuando se recoge efectivo de terceros que debería ser depositado en la institución financiera y se desvía para otros fines, se está cometiendo un robo, una ocultación, y una manipulación de los registros de la institución financiera.

Nuria Pina-Barrajón (2012, pp. 7-8) explica que para que haya estafa concurren, entre otros, engaño idóneo o adecuado para provocar error del sujeto pasivo, lo que lo lleva a actuar bajo una falsa realidad por la cual se produce el traspaso patrimonial con el consiguiente perjuicio para el disponente, el ánimo de lucro como motivo para realizar el fraude y la relación de causalidad entre el engaño provocado y el perjuicio experimentado, lo que implica que el dolo del agente tiene que anteceder o ser concurrente con la actividad fraudulenta.

Todos los elementos descritos suelen aparecer en el fraude de banca paralela en el que el empleado hace creer al cliente que los fondos que él entrega son recibidos por el banco, o viceversa, y el empleado defraudador se queda con las cantidades del cliente.

2. La falsedad documental, como indican Nuria Pina-Barrajón (2012, p. 5) y Juan Manuel Rodríguez-Zarco (1991, pp. 57-130), implica la alteración o simulación de un documento en alguno de sus elementos o requisitos de carácter esencial, de manera que induzca a 
error sobre su autenticidad; suponiendo en un acto la intervención de personas que no la han tenido o atribuyendo a las que han intervenido en él declaraciones o manifestaciones diferentes de las que habrían hecho; alterando registros contables, recurriendo al uso ilegal de los mismos, la ocultación de transacciones efectivamente realizadas en los registros contables o el registro contable de transacciones no realizadas.

En el fraude de banca paralela se dan varios de estos elementos como medio o como finalidad en el engaño, ya que el empleado justifica la operación entregando al cliente documentos falsos (contratos, informes financieros fraudulentos, etc.) que simulan los que el banco emite.

3. La corrupción y el soborno no son hechos aislados (KPMG, 2013, p. 29) y aparecen habitualmente en la banca paralela desde una doble perspectiva. En primer lugar, porque el empleado defraudador sea extorsionado o sobornado para llevarla a cabo. En segundo lugar, el destino de los fondos obtenidos puede ser el soborno o la extorsión de terceros, como finalidad última del fraude o como medio para evitar que se descubra.

4. La evasión fiscal igualmente es un fin y una causa muy frecuentes en la banca paralela. En ocasiones, como se pone de manifiesto en la tabla 1, la opacidad fiscal de las operaciones es el motivo para que los clientes confíen en el defraudador. Pero, con independencia de la connivencia o no del depositante, todos los fondos e inversiones sin registro oficial en el banco quedan al margen de la supervisión de la autoridad fiscal.
5. Entre el resto de fraudes que pueden aparecer, el lavado de activos es uno de los más frecuentes, al servir como medio de ocultación de los fondos obtenidos de actividades ilícitas. Asimismo, los fondos obtenidos fraudulentamente pueden estar financiando otras actividades ilícitas.

\section{Perfil del defraudador y de los intervinientes en el fraude}

Como ya se ha anticipado, el estafador que comete un fraude por banca paralela posee un perfil característico que facilita la realización del delito:

- Trabaja para un banco, lo que facilita el acceso a inversores para captar su confianza y su dinero.

- Puede manejar efectivo y, en los casos expuestos con anterioridad, desempeñaba mayoritariamente el puesto de director de la sucursal bancaria, como se muestra en el gráfico 4. De esta forma, tenía acceso y conocimiento cualificado a todos los clientes de la oficina. En este sentido, PwC (2015, p.15) indica que solo el $22,2 \%$ de los fraudes internos son cometidos en España por empleados de menor rango jerárquico.

- El puesto ocupado en la organización suele implicar una antigüedad en la misma y cierta edad. Estas hipótesis para el fraude de banca paralela igualmente concuerdan con los datos de la más reciente encuesta sobre fraude realizada para España por PwC (2015, p. 15), en la que el defraudador interno tenía una antigüedad de más de 10 años en la empresa en un $47,2 \%$ de los casos y una edad superior a 40 años en el $61,1 \%$ de los casos. 


\section{Puesto del empleado defraudador}

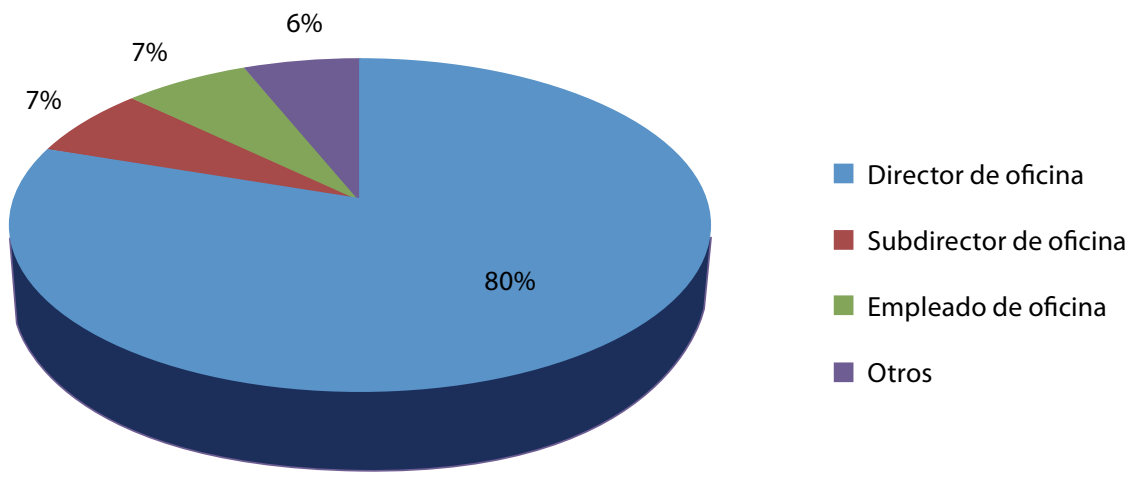

Gráfico 4

Puesto de trabajo del empleado defraudador por banca paralela en España

Fuente: elaboración propia, a partir de los casos descritos en la tabla 1

- Como señala Nicolás Darío Ramírez-

Moncada (2009, p. 282), el fraude en los

bancos ha evolucionado, apareciendo el empleado "tecnofraucrata", bien preparado, buen conocedor de los negocios, de los mercados, de los procedimientos y de los sistemas de la institución y que, además, tiene a su disposición tecnología muy evolucionada que permite la perfecta simulación de documentación mercantil. En este sentido, $\mathrm{PwC}$ (2015, p. 15) indica que en España el 61,1\% de los defraudadores internos poseía titulación universitaria superior.

- Desde el punto de vista ético, el empleado desleal habitualmente no muestra reparos en ganar dinero sin importarle los medios para conseguirlo.

De esta forma, en el empleado-defraudador confluyen ciertos rasgos: elevada formación técnico-profesional, cierta edad y antigüedad en la empresa y acceso a tecnología avanzada para falsificar documentación física o electrónica. A estas características hay que añadirle un escaso nivel ético o moral que le permite racionalizar un fraude prolongado en el tiempo con múltiples estafados.

El gráfico 5 presenta los perfiles característicos del resto de los intervinientes, estafadores, estafados o simplemente beneficiados en el fraude por banca paralela, voluntaria o involuntariamente y cada una de las tipologías identificadas se describe a continuación.

1. Estafados no cooperantes. El primer bloque de intervinientes en el fraude son los clientes que no conocen el fraude. En este grupo se encuentran tres tipos de involucrados:

a. Sujetos que han planteado una inversión al defraudador confiando en que la realizaban por medio del banco. 


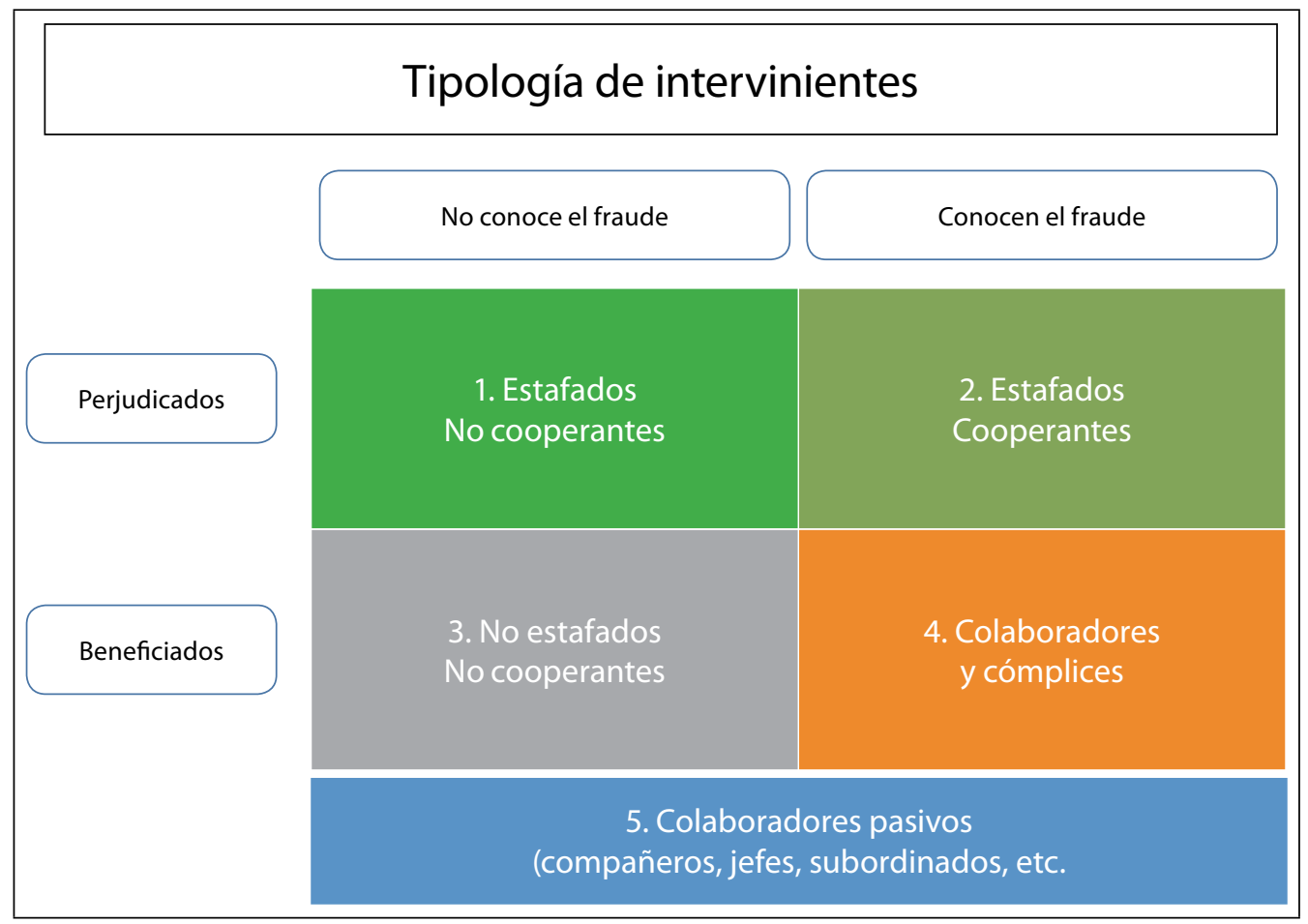

\section{Gráfico 5}

Tipología de intervinientes en el fraude interno de banca paralela Fuente: elaboración propia

b. Sujetos que, sin plantear operación alguna, sufren la apropiación indebida de los saldos de sus cuentas.

c. Sujetos a los que se les concede un préstamo sin solicitarlo ni conocerlo y, por lo tanto, sin disfrutar de su importe.

Las características frecuentes de estos intervinientes son: edad avanzada, ausencia de familiares cercanos, escasa cultura financiera, emigrantes y no residentes que pasan largos períodos fuera de la localidad en la que opera el estafador, clientes que no operan por internet y realizan parte de sus operaciones bancarias en efectivo, etc. Estas características, individualmente o combinadas entre sí, los hacen especialmente vulnerables al delito de apropiación indebida.

2. Estafados cooperantes. Entre los clientes que conocen el fraude y son perjudicados por él están los que saben que la inversión que se les ofrece no la realiza el banco y colaboran en el engaño a cambio de tipos de interés superiores a los del mercado, opacidad fiscal de los rendimientos u otros beneficios, pero no recuperan la totalidad de la inversión. En este grupo es más difícil encontrar perfiles típicos, excepto el móvil que los une: la codicia y un escaso nivel moral.

3. No estafados no cooperantes. En principio, podría parecer que todos los clientes que 
no conocen el fraude son perjudicados. No obstante, en especial en fraudes complejos, duraderos o con muchos afectados, pueden aparecer clientes involucrados en el fraude de manera pasiva cuyas cuentas son utilizadas sin su conocimiento para ocultar saldos o movimientos y blanquear así el efectivo sustraído. Las características personales de estos clientes son muy similares a las descritas en el grupo de estafados no cooperantes.

4. Colaboradores y cómplices. Son clientes y/o terceros que conocen perfectamente el fraude y resultan beneficiados de él. En este colectivo están aquellos clientes que conscientemente entregaron sus fondos al defraudador y han podido recuperar la inversión y los intereses prometidos. Igualmente, aparecen extorsionadores o sobornadores del defraudador con quienes tiene que compartir los importes estafados, testaferros del defraudador, socios, etc. En la tabla 1 aparecen casos con multitud de detenidos, lo que ofrece una idea de las redes de delincuentes que en ocasiones rodean la banca paralela.

5. Colaboradores pasivos. Por último, como no intervinientes en el fraude, pero colaborando pasivamente, pueden aparecer subordinados o jefes del defraudador que, percibiendo indicios suficientes de fraude, no lo denuncian.

\section{Guía para la prevención del riesgo de banca paralela}

La exposición de las instituciones financieras al fraude de banca paralela depende del tipo de ne- gocios o de operaciones que realizan (por ejemplo, la banca retail y la que realiza operaciones de efectivo con clientes presenta niveles de exposición superiores a la banca mayorista). A continuación, desarrollamos las principales medidas para la prevención del fraude de banca paralela: el programa de gestión del fraude, la evaluación del riesgo y las medidas de mitigación.

\section{a. Programa de gestión del fraude}

El punto de partida en la prevención del fraude en general es un programa eficaz de gestión del fraude (IAI, 2015, p. 35; IIA, AICPA \& ACFE, 2008 , p. 19) que debe contener los siguientes elementos concretos para la banca paralela:

- Política escrita para transmitir todas las exigencias y expectativas por parte de la alta dirección en relación con el fraude de banca paralela.

- Una evaluación periódica del riesgo de fraude, que identifique los eventos potenciales que la organización necesita mitigar en función de las particularidades que la banca paralela adquiera en el sector, en los países de actuación, etc.

- Unas medidas de prevención que mitiguen la comisión del delito y su impacto en la organización: las responsabilidades, los indicadores de fraude y los controles.

- Unas medidas de detección, que descubran fraudes cuando fallen las medidas de prevención.

- Un proceso de documentación y reporting, que permita reunir la información necesaria para acreditar, en su caso, el potencial fraude y que garantice el enfoque coordinado, adecuado y oportuno de la investigación. 


\section{b. Evaluación del riesgo de fraude por banca paralela}

En el programa de gestión del fraude, uno de los principales elementos en la prevención es el análisis de los riesgos a los que está expuesta la organización. En el caso de las instituciones financieras y la banca paralela, se evalúa el riesgo de fraude desde la perspectiva de dónde, cómo y por quién puede cometerse este tipo de fraude.

El diagnóstico del riesgo de fraude incluye, generalmente, cuatro pasos:

1. Identificación del riesgo inherente de fraude.

2. Mapeo de controles existentes con los posibles esquemas de fraude y prueba de eficacia.

3. Identificación de áreas de mejora.

4. Documentación y reporting de la evaluación del riesgo de fraude.

En el análisis de estos pasos para el fraude de banca paralela, debido a las características descritas, la evaluación del riesgo incluye otra serie de riesgos de fraude que de forma conjunta o aislada pueden aparecer en la organización.

\section{Identificación del riesgo de fraude de banca paralela}

Como se ha expuesto, la banca paralela es un fraude que generalmente contiene varias irregularidades interrelacionadas entre sí. Por tanto, la identificación de los riesgos constituye una herramienta útil para la evaluación del riesgo de fraude de banca paralela y conocer sus probables componentes.

En la identificación del riesgo de fraude se utilizan datos históricos internos y datos externos. La obtención de datos externos resulta complicada debido al secreto y la discreción que sustentan el principio de confianza bancario. Además, como señala Julio Fernández-Sanguino Fernández (2000), el conocimiento del fraude se complica debido a la confidencialidad con que las empresas tratan los actos indebidos que se producen en ellas.

Debido a la incorporación del riesgo operacional en la normativa sobre requerimientos de capital para las instituciones financieras y a las recomendaciones para la gestión de este riesgo (Comité de Supervisión Bancaria de Basilea, BIS, 2006, 2011), se han creado plataformas en las que, de manera agregada y confidencial, los bancos tratan datos estadísticos de eventos de pérdida, entre los que se incluyen los fraudes internos. Estas plataformas, como el Consorcio Español de Riesgo Operacional (Grupo Cero) o el Consorcio Latinoamericano de Pérdidas por Riesgo Operacional (CLPRO), pueden comenzar a ser una fuente externa de información cuantitativa para la identificación de las bancas paralelas.

Asimismo, cuando el fraude alcanza magnitudes importantes (por su importe o por el número de afectados) se convierte en objeto de atención de los medios de comunicación. En estos casos, la revisión de la hemeroteca es otra fuente de información externa, más cualitativa que cuantitativa y, en ocasiones, única para conocer el suceso.

\section{Las fuentes históricas internas son las} más apropiadas. Los antecedentes de fraude en la propia institución financiera, normalmente, provocan investigaciones que documentan los fraudes sufridos, los fallos en los controles y las mejoras que se han propuesto. 
Las entrevistas con los responsables de las sucursales - personal clave en la banca paralela- son herramientas recomendables para identificar este riesgo. Estas entrevistas pueden tener un doble enfoque: a) detectar los procesos u operaciones en las que se pueden realizar los distintos tipos de fraude que pueden aparecer en la banca paralela (ocultación de ingresos, manipulación de justificantes, etc.) y b) constatar con los responsables de las sucursales la bondad de los controles existentes.

Adicionalmente, se deberá identificar la tipología de riesgos individuales que combinados entre sí pueden provocar un fraude de banca paralela. Así, por ejemplo, si la institución financiera no ha identificado riesgo de apropiación indebida de ingresos, por no aceptar ingresos en efectivo en sus procesos y/o sucursales, deberá analizar qué otros riesgos individualmente identificados podrían provocar una banca paralela (como desvío de fondos de cuentas de clientes, uso de cuentas contables transitorias, cuentas inactivas, etc.).

El proceso de identificación de los riesgos de fraude debe terminar con la construcción de una matriz de probabilidad de ocurrencia (probable, posible o remota) e impacto (significativo o no significativo). No solo se debe tener en cuenta el impacto económico, sino también el reputacional y el legal.

\section{Mapeo de controles existentes}

Una vez identificados los riesgos inherentes a la actividad de la institución, es necesario determinar la bondad y frecuencia de los controles sobre los distintos fraudes individuales y si hay controles específicos para el fraude global de banca paralela. Así se obtiene, para cada riesgo inherente identificado, un riesgo residual (Banco de España, 2012), que es el riesgo que queda en la organización una vez aplicados todos los controles. El nivel deseado de riesgo residual se denomina "tolerancia al riesgo" o "apetito de riesgo" (IAI, 2013), definido como "el riesgo que se está dispuesto a aceptar en la búsqueda de la misión/visión de la entidad". La dirección y los órganos responsables deben establecer y aprobar el apetito de cada riesgo.

\section{Identificación de áreas de mejora y reporting}

El mapeo de controles va a permitir recalcular probabilidad de impacto y ocurrencia de la matriz de riesgos, en función de la existencia o no de un control para cada riesgo, su bondad y su frecuencia. Este recálculo pondrá de manifiesto aquellas áreas de mejora y permitirá priorizarlas.

Esta priorización debe considerar que los bancos no pueden eliminar por completo el riesgo de banca paralela y, para no caer en ineficiencias, realizar un análisis coste-beneficio de mitigación de riesgos.

El resultado de la evaluación del riesgo se resume en un informe objetivo, sin opiniones ni juicios de valor, que debe ser el punto de partida de un proceso de diálogo transversal en la institución para la realización de un plan de acción que reduzca el riesgo de fraude de banca paralela.

El resumen de la propuesta planteada correspondiente a la parte de evaluación del riesgo se muestra en la tabla 2 . 


\begin{tabular}{|c|c|}
\hline \multicolumn{2}{|c|}{ Guía para la prevención del fraude por banca paralela } \\
\hline \multicolumn{2}{|r|}{ Evaluación del riesgo } \\
\hline \multirow[t]{12}{*}{ Identificación del riesgo inherente } & Fraude múltiple, "megafraude" \\
\hline & Identificación de riesgos individuales \\
\hline & Fuentes externas \\
\hline & - El problema de la ausencia de estadísticas \\
\hline & - Prensa \\
\hline & - Riesgo operacional \\
\hline & Fuentes internas \\
\hline & - Historial de casos en el banco \\
\hline & - Entrevistas con personal clave \\
\hline & Matriz de riesgos \\
\hline & - Ocurrencia (probable, posible, remota) \\
\hline & - Impacto (económico, legal y reputacional) \\
\hline \multirow[t]{4}{*}{ Mapeo } & Bondad y frecuencia de controles \\
\hline & Riesgos individuales y de banca paralela \\
\hline & Recálculo de la matriz de riesgos \\
\hline & Riesgo residual - Tolerancia al riesgo \\
\hline \multirow{2}{*}{$\begin{array}{l}\text { Identificación de áreas de mejora y } \\
\text { reporting }\end{array}$} & Imposibilidad de eliminar totalmente el riesgo \\
\hline & Análisis coste-beneficio \\
\hline
\end{tabular}

Tabla 2

Guía para la prevención del fraude - evaluación del riesgo Fuente: elaboración propia

\section{c. Mitigación del riesgo de fraude por banca paralela}

La mitigación de la banca paralela comienza con la ejecución de la denominada política de prevención del fraude, un programa específico de controles y medidas tanto preventivas como detectivas. La política de prevención del fraude en la institución financiera debe abordar los siguientes contenidos:

- Definición del ámbito de aplicación, que debe alcanzar a toda la institución, sus filiales y también debe definir en qué medida afecta a las personas que trabajan en el banco y personas allegadas.
- Principios de actuación de la institución contra el fraude.

- Definición de fraude y un detalle no taxativo de las conductas que suponen fraude. En este apartado se deberá definir la banca paralela con la tipología de fraude que la compone.

- Definir la función de prevención del fraude en la entidad y sus responsables.

- Definir la función de investigación del fraude en la institución y sus responsables.

- Establecer las consecuencias y acciones a llevar a cabo cuando se detecte y confirme un fraude. 
- Incluir los procedimientos de comunicación de la propia política.

- Procedimientos y responsables del control, evaluación y revisión de la política.

Definida la política de prevención del fraude, se deberán construir e implementar alertas e indicadores de fraude de banca paralela. Para ello es necesario conocer bien la casuística que puede dar lugar a una banca paralela y las tipologías de fraude que le son propias. La función de prevención del fraude usualmente recae sobre los departamentos de seguridad o auditoría interna.

Los indicadores de fraude de banca paralela se fundamentan en la teoría del triángulo del fraude y sus tres elementos: la oportunidad percibida, el motivo (incentivo/presión) y la racionalización. Algunos de estos indicadores generales (IAI, 2015, p. 93) aplicables a la banca paralela son:

- Situación financiera del empleado comprometida.

- Estilo de vida por encima de sus posibilidades.

- Inclinación por las apuestas o juegos de azar.

- Abuso de alcohol o drogas.

- Relación estrecha con personas convictas o de dudosa reputación.

A continuación, se enumeran indicadores específicos, no taxativos, que pueden alertar sobre la posibilidad de existencia de banca paralela, y que explican brevemente su motivo:

- No ausentarse nunca del puesto de trabajo, no tomar días de vacaciones o acudir al trabajo en días de vacaciones con excusas. El empleado-defraudador no puede permitir que en su ausencia los clientes estafados intenten realizar una gestión relacionada con las operaciones fraudulentas.

- Elevadas incidencias de correspondencia devuelta de clientes en la oficina. En la banca paralela es frecuente que las comunicaciones reales de extractos, operaciones, posiciones, etc., no lleguen al cliente para que no descubra que sus saldos no son correctos o que las operaciones ordenadas no se han realizado. Para ello, el defraudador suele modificar las direcciones de los clientes en la base de datos corporativa e indicar direcciones erróneas.

- Clientes "cautivos" que únicamente realizan gestiones con el empleado desleal y se niegan a realizar operaciones con otros empleados. El empleado que realiza el fraude de banca paralela suele escoger a los clientes de los que va a detraer fondos (edad avanzada, baja cultura financiera, etc.) y los convence para ser atendidos siempre por él mismo. Se evita así que el cliente descubra que sus saldos y operaciones no son correctos.

- Cumplimiento de objetivos comerciales de forma rápida y holgada, sobresaliendo del resto de sucursales de la institución. Para determinados empleados, una de las motivaciones es su propio ego, realizando la operatoria de banca paralela para el cumplimiento de objetivos comerciales. En otras ocasiones, el empleado quiere pasar desapercibido y cumple objetivos para no levantar sospechas en sus superiores.

- Realizar operaciones por cuenta de terceros como mandatario, sin que los terceros estén 
presentes o nadie en la sucursal los conozca. El empleado que realiza la banca paralela se apropia de fondos de clientes (en efectivo o por medio de operaciones bancarias) y los puede utilizar para conceder préstamos o facilidades de liquidez a terceros. Tiene que realizar estas operaciones al margen de los clientes, por tanto, debe simular que las está realizando un tercero.

- Realización de operaciones de efectivo en puestos de la sucursal no acondicionados para ello. Por normativa de seguridad, únicamente ciertos puestos de trabajo están acondicionados para realizar operaciones con efectivo. La realización de operaciones con efectivo en puestos no acondicionados, como el despacho del director de la sucursal, puede ser un indicador de que se estén ocultado operaciones.

- Excesivo uso de cuentas contables transitorias en la sucursal. Aunque normalmente la banca paralela no presenta ningún nexo de unión con la contabilidad de la entidad, algunos empleados defraudadores se ayudan de cuentas transitorias o cuentas puente para llevar el registro de las operaciones que realizan.

- Desviaciones de solicitudes de dinero de la sucursal respecto a la media de sucursales de su entorno. La realización de la banca paralela puede suponer la necesidad de disponer de más cantidad de dinero en efectivo en la sucursal bancaria en comparación con otras sucursales con un volumen de negocio similar.

- Existencia de justificantes de operaciones y contratos con la misma firma o con firmas si- muladas. Los controles básicos bancarios identifican operaciones no firmadas, por lo que el empleado defraudador simula o inventa las firmas de los clientes en las operaciones y en los contratos.

- Pago repentino de operaciones en situación de morosidad. El pago con aportación de fondos en efectivo de operaciones crediticias que están impagadas desde hace tiempo es un indicador a revisar. El empleado defraudador puede pagarlas con fondos provenientes de terceros en connivencia con el moroso.

- Operaciones crediticias que quedan impagadas desde su concesión o en sus primeros meses. Pueden ser indicadores de operaciones simuladas para dotar de liquidez la banca paralela, y se realizan sobre clientes ficticios o por personas interpuestas insolventes.

- Elevado número de clientes que atienden las cuotas de sus operaciones crediticias en efectivo sin mantener otra vinculación con la entidad.

Para los responsables de la prevención del fraude en las instituciones, resulta útil incorporar estos indicadores a los sistemas de prevención y analizar la forma de medirlos en cada banco en particular.

El siguiente paso es el establecimiento de controles para mitigar la posibilidad de que se produzca una banca paralela, adaptados al número de operaciones y los procesos de cada banco. Dadas las características de la banca paralela, la clave en la implantación de los controles está en la adecuada segregación de funciones. De esta manera, se evita que un solo empleado gestione cualquier proceso o cliente. 
A continuación, se detallan los controles típicos que se consideran relevantes para mitigar el fraude de banca paralela en función de los indicadores descritos.

Controles sobre operaciones y saldos con clientes

- Los cambios de domicilios en clientes deben ser verificados, para comprobar que esos cambios no provocan devoluciones de la correspondencia.

- Los justificantes de operaciones, cuentas, etc., deben ser remitidos al cliente por servicios distintos a la propia oficina, para que esta no pueda retenerlos.

- La institución debe realizar procedimientos de confirmación y conciliación periódica y aleatoria de saldos y movimientos con clientes, independientes de las realizadas por auditores externos o internos. Las incidencias deben ser tratadas centralizadamente por departamentos administrativos, financieros o de control.

- Impedir a los empleados la realización de operaciones por cuenta de terceros no presentes en las instalaciones del banco.
Controles específicos sobre operaciones crediticias

- Análisis centralizado de operaciones crediticias atrasadas o morosas desde su concesión.

- Procedimientos de doble autorización de las operaciones crediticias.

- Comprobación centralizada de operaciones con cuotas periódicas pagadas siempre en efectivo.

Controles de recursos humanos

- Política de rotación de responsables de oficinas y de fijación de períodos máximos de ocupación de puestos en oficinas de una misma localidad.

- Control de ausencias y vacaciones de los empleados.

- Cumplimiento del código ético de la entidad.

La tabla 3 muestra el resumen de la política de prevención, indicadores y controles de la guía de prevención del riesgo de fraude por banca paralela propuesta en el presente documento.

\begin{tabular}{|c|c|}
\hline \multicolumn{2}{|r|}{ Guía para la prevención del fraude por banca paralela } \\
\hline \multicolumn{2}{|r|}{ Guía de prevención } \\
\hline \multirow{8}{*}{ Política de prevención } & Ámbito: toda la organización \\
\hline & Principios contra el fraude \\
\hline & Definición de banca paralela \\
\hline & Función de prevención y responsable \\
\hline & Función de detección y responsable \\
\hline & Consecuencias cuando ocurre el fraude \\
\hline & Comunicación de la política \\
\hline & Procedimientos de control y responsable \\
\hline
\end{tabular}


PROPUESTA de UN MOdELo PARA LA PREVENCIÓN / J. ARCENEGUI, J. MARTín, v. ObRERo / 645

\begin{tabular}{|c|c|}
\hline \multicolumn{2}{|r|}{ Guía para la prevención del fraude por banca paralela } \\
\hline \multicolumn{2}{|r|}{ Guía de prevención } \\
\hline \multirow{18}{*}{ Indicadores } & Generales del empleado sospechoso \\
\hline & - Situación financiera comprometida \\
\hline & - Estilo de vida por encima de sus posibilidades \\
\hline & - Jugadores de azar \\
\hline & - Problemas con el alcohol y las drogas \\
\hline & - Relación con personas de dudosa reputación \\
\hline & Específicos de la banca paralela \\
\hline & - Ausencia de vacaciones y descansos \\
\hline & - Correspondencia devuelta de clientes \\
\hline & - Clientes "cautivos" del empleado sospechoso \\
\hline & - Cumplimiento de objetivos comerciales \\
\hline & - Operaciones de terceros sin estar presentes \\
\hline & - Operaciones de efectivo en puestos inadecuados \\
\hline & - Uso excesivo de cuentas transitorias \\
\hline & - Falsificación de firmas en contratos y operaciones \\
\hline & - Operaciones atrasadas pagadas en efectivo \\
\hline & - Operaciones crediticias impagadas desde su inicio \\
\hline & - Operaciones de efectivo de clientes sin vinculación \\
\hline \multirow{14}{*}{ Controles } & Principio de segregación de funciones \\
\hline & Operaciones y saldos con clientes \\
\hline & - Control centralizados de cambios de direcciones de clientes \\
\hline & - Envío centralizado de extractos bancarios a clientes \\
\hline & - Conciliación y confirmación periódica de saldos y movimientos de cuentas con clientes \\
\hline & - Prohibir operaciones de terceros no presenciales \\
\hline & Operaciones crediticias \\
\hline & Concesión centralizada de operaciones \\
\hline & Doble autorización de operaciones crediticias \\
\hline & Control centralizado de pagos en efectivo \\
\hline & Recursos humanos \\
\hline & - Rotación de personal \\
\hline & - Control de ausencias y vacaciones \\
\hline & - Cumplimiento del código ético \\
\hline
\end{tabular}

Tabla 3

Guía para la prevención del fraude de banca paralela - Política de prevención, principales indicadores y controles Fuente: elaboración propia 


\section{d. La eficacia de los códigos éticos en la lucha contra el fraude}

El aumento de la sensibilidad de los stakeholders ante los escándalos o fraudes financieros ha provocado una corriente general de aprobación de políticas de responsabilidad social corporativa (RSC) y códigos éticos (MuñozMartín, 2013). Hay planteamientos doctrinales enfrentados sobre la utilidad de las normas éticas. Quienes señalan que negocios y ética son irreconciliables (Berzosa, 2013), opinan que los códigos éticos carecen de valor preventivo. Por el contrario, quienes defienden que hay que hacer un esfuerzo que facilite el entendimiento entre ambas disciplinas (Sen, 1989) ven útiles estos instrumentos para mejorar el entorno interno de empleados y stakeholders (Arredondo-Trapero, Garza-García \& Villa-Castaño, 2014; Baracaldo-Lozano, 2013, p. 602).

La eficacia de los códigos éticos en la prevención del fraude por banca paralela se centraría en tres cuestiones principales: ¿es suficiente la existencia del código de conducta en la organización para garantizar el comportamiento ético e impedir las conductas de fraude en los empleados?, ¿es una prioridad para los bancos que los códigos éticos sean conocidos y asumidos por los empleados?, ¿las medidas coercitivas son más adecuadas que las medidas de sensibilización y formación continua en los aspectos concernientes a la ética del trabajador?

En nuestra opinión, la existencia de códigos éticos en los bancos es condición necesaria pero no suficiente para garantizar el comportamiento correcto de los empleados. En su mayoría, los códigos éticos regulan genéricamente las prácticas de los empleados en el trato con clientes $^{3}$ (Rodríguez \& Díaz, 2004).

La condición suficiente sería el conocimiento y la asunción del código por parte de los empleados como prioridad para el banco. El proceso de formación continua constituye el patrimonio moral de la organización (Arredondo-Trapero, Garza-García \& VázquezParra, 2014) y posiblemente la formación en valores y ética profesional sea la más importante, en especial en el ámbito financiero que tantas desconfianzas ha generado en el inversor (Ansótegui, Gómez-Bezares \& González-Fabre, 2014).

La tercera cuestión plantea un falso dilema aplicado al fraude de banca paralela. La doctrina clásica debate sobre dos posibles esquemas éticos en la empresa (Hartman, Desjardins \& Espinoza, 2011): el modelo del estricto cumplimiento de la norma frente al de una cultura basada en valores que premien la actitud ejemplar del individuo. En nuestra opinión, los dos modelos son complementarios: la conducta ejemplar debe ser incentivada, pero el delito y el fraude no deben ser permitidos. En este sentido y conectando con la idea de la prioridad de

\footnotetext{
3 Son ejemplos comunes a la mayoría de códigos existentes en los bancos españoles: La prohibición de realizar operaciones con clientes que puedan beneficiar a empleados a título personal, así como la solicitud o aceptación de cualquier tipo de pago, comisión, regalo o retribución que proceda de clientes, proveedores o cualquier intermediario. La contratación de los productos y servicios en la forma establecida en los procedimientos internos, obteniendo y conservando la documentación requerida y entregando, cuando proceda, copia de la misma a los clientes. La obligación de los empleados de utilizar los recursos del banco de forma eficiente y apropiada, y únicamente para el desempeño de su actividad profesional en el banco o para los supuestos previstos en la normativa interna.
} 
la lucha contra el fraude, es muy común que los empleados conozcan la existencia de una banca paralela por los medios de comunicación o la propia clientela; son escasos los ejemplos de bancos que priorizan la información interna como medida preventiva de futuros fraudes.

El temor al conocimiento de la existencia de bancas paralelas también paraliza la comunicación interna. Es cierto, como señalan Elsa González-Esteban y Domingo García-Marzá (2006), que la credibilidad social de una empresa quedará sujeta a la conducta moral o inmoral de sus trabajadores. Igualmente, la relación que los empleados deben tener entre integridad personal y desempeño del trabajo es un aspecto cada vez más valorado por la clientela de un banco para realizar una elección adecuada (Ibarra, 2002). Por tanto, los bancos deben dar muestras de la presencia del elemento ético en sus organizaciones y empleados, y de si su comportamiento es socialmente responsable o no (Rodríguez-Gutiérrez, FuentesGarcía \& Sánchez-Cañizares, 2013). Pero, en nuestra opinión, la ocultación de los hechos o la realización de una comunicación interna o externa sesgada de ellos solo produce el efecto contrario al perseguido en la clientela.

\section{Investigación del fraude de banca paralela}

El inicio de la investigación del fraude parte de la comunicación del mismo, con los medios establecidos internamente por la institución (canal de denuncias), de la comunicación de terceros (anónimo, reclamación de clientes, reguladores, auditoría externa, etc.), o la detec- ción con los controles establecidos o las labores de supervisión de la auditoría interna.

La investigación de un fraude pretende contestar las típicas preguntas: qué, cómo, por qué, quién y cuándo.

\section{a. Protocolo de actuación}

En su programa de gestión del fraude, el banco debería definir un protocolo de actuación, que contemple las siguientes fases:

1. Evaluación preliminar del indicio de fraude: concluye si es necesario continuar la investigación o archivar la sospecha. Para ello, se tendrán en cuenta los antecedentes de la persona inicialmente identificada o denunciada como posible autor del fraude, solicitud de mayor información si la denuncia no es anónima y comprobación de su razonabilidad.

2. Valoración de la suspensión del empleado investigado: la piedra angular de la banca paralela es el control de las operaciones por parte del defraudador, por lo que la suspensión del empleado y el corte de operaciones "paralelas" que provoca es indispensable para poder identificar el alcance del fraude. Asimismo, puede considerarse conveniente apartar al resto de empleados que trabajaban conjuntamente con el defraudador, bien por la posibilidad de que estén involucrados; bien porque, sin ser conscientes, estén dando cobertura a la realización del fraude.

3. Valoración del liderazgo y composición del equipo investigador: en función de los recursos de la institución, la competencia de sus empleados y la complejidad y alcance 
del posible fraude. Se deben definir los partícipes en la investigación y su responsabilidad. La participación de un auditor externo es recomendable si finalmente se judicializa la investigación, realizando pruebas sustantivas y de auditoría forense para que su informe pueda ser usado como prueba pericial.

Normalmente, en la investigación del fraude de banca paralela suele ser necesaria la participación de un equipo multidisciplinar interno que gestione la situación (gabinete de prensa para tratar con los medios de comunicación, negocio y atención al cliente para resolver las incidencias con clientes afectados, asesoría jurídica para valorar la posición jurídica del banco y la posible comisión de delitos por parte del empleado, que hagan necesaria su comunicación a la autoridad competente, auditoría interna, recursos humanos, etc.).

4. Determinación de las personas a las cuales se va a comunicar el inicio de la investigación: qué superiores jerárquicos y compañeros del empleado investigado van a conocer los hechos y en qué momento. Se recomienda no comunicar en el caso de que no se tenga definido el perímetro de implicación de personas en el fraude.

5. Definición de los hitos y etapas de la investigación: con la flexibilidad que los trabajos de auditoría forense exigen (Badillo-Ayala, 2008, p. 15).

6. Definición del reporting intermedio y final: el protocolo determinará los momentos y niveles de reporting, y la evaluación de las conclusiones intermedias y finales de la in- vestigación, incluyendo los destinatarios y las áreas que deben valorar las mismas (alta dirección, recursos humanos, asesoría jurídica, contabilidad, etc.).

La participación de la asesoría jurídica a lo largo de la investigación es clave para abordar los aspectos legales. Asimismo, el área contable tomará un papel preponderante cuando se vaya determinando la necesidad de reponer los saldos apropiados a clientes y sea necesaria la correcta contabilización del gasto y las provisiones correspondientes conforme a la NIC37 (IASB, 2012) o la norma 37 de la Circular 4/2004 (Banco de España, 2004) ambas coincidentes ${ }^{4}$.

La investigación de una banca paralela se puede dividir en las siguientes etapas: planificación, investigación y comunicación de resultados. A continuación se analiza cada una de ellas.

\section{b. Planificación}

El fraude de banca paralela se caracteriza, como hemos indicado, por la realización de transacciones al margen de la contabilidad y registros de la institución. La obtención de información preliminar sobre las operaciones ocultas, los procedimientos empleados, los clientes afectados o el modus operandi es el objetivo

4 El banco suele contabilizar como gasto las cantidades defraudadas que va restituyendo a clientes y terceros una vez probado el fraude, dado que la posibilidad de recuperación de estos importes suele ser remota mediante la reclamación, denuncia y futura condena al defraudador. Adicionalmente, se suelen dar las circunstancias para constituir provisiones por las cantidades que probablemente haya que restituir a clientes y terceros en el futuro, y de informar en la memoria de las cuentas anuales de estas circunstancias. 
principal de la planificación. La información previa irá determinando el alcance del fraude, $y$ permitirá realizar una estimación inicial de cuantificación del posible quebranto económico, legal o reputacional para el banco.

El desconocimiento inicial del alcance del fraude provoca que en este tipo de trabajos forenses no se aplique materialidad o importancia relativa en el análisis de operaciones o transacciones. Como indican José Armando López-Rubiano y Elsa Milena Mora-Pedraza (2006, p. 117), la investigación de los fraudes por banca paralela conllevan actuaciones auditoras muy especiales, "no siendo limitante la materialidad", al menos al inicio de la misma.

La recopilación de información puede ser compleja e incluso quedar incompleta si el empleado defraudador no colabora con la misma o incluso destruye pruebas. Al inicio de la investigación es necesario planificar los procedimientos de salvaguarda de la información y se deben tomar las medidas oportunas para proteger y custodiar cualquier fuente de información relevante para la investigación (custodia física de documentos, computadores o cualquier otro dispositivo electrónico, grabaciones de cámaras de seguridad, etc.), para evitar su manipulación por personas ajenas a la investigación.

La entrevista con el posible empleado defraudador, que de forma habitual se realiza en la fase de investigación, se debe planificar y preparar lo más pronto posible. La preparación de la entrevista comienza con la obtención de información del posible empleado defraudador existente en otras áreas de la institución. El apoyo de la asesoría jurídica de la institución en la entrevista, y la valoración jurídica de la información obtenida y las futuras actuaciones son muy importantes, debido a la posible existencia de terceros perjudicados o beneficiados y un posible delito del cual informar a la autoridad competente.

Junto con la entrevista, y en la fase de obtención de información, se deberán determinar todas las posibles fuentes de información internas. Por la habitual ausencia de registros internos es vital la intervención de los sistemas informáticos, conforme las indicaciones de asesoría jurídica para que puedan servir como prueba judicial. La intervención notarial de los medios informáticos y la replicación de discos duros para aplicar herramientas informáticas forenses son recomendables en esta fase.

Si el empleado desleal ha ocultado el registro de las transacciones en cuentas contables transitorias, cuentas de orden, o cuentas de clientes abandonadas o sin saldos, es necesario revisar el diario contable de las operaciones realizadas por el empleado.

En las investigaciones por banca paralela las fuentes externas suelen ser más fructíferas que las fuentes internas. La entrevista con clientes o terceros identificados previamente como posibles perjudicados y/o beneficiados puede ser, en algunos casos, la única fuente de información. Igualmente es necesaria la consulta de los registros públicos de administradores y accionistas y cualquier otro tipo de información de las personas jurídicas afectadas.

La última fase de la planificación es el análisis preliminar sobre cuáles serán los objetivos principales de la investigación, la metodología a utilizar y las comunicaciones a realizar. Asimismo, se definirán las líneas principales y secundarias de la investigación. 


\section{c. Desarrollo de la investigación}

Como señala el IAI (2015), esta fase de la investigación debe concluir con la comprensión de las siguientes incógnitas:

- Autores materiales, inductores y/o cooperadores del fraude, si los hay.

- Valoración de la dimensión del fraude mediante su cuantificación económica, legal y reputacional.

- Conocer el modus operandi del defraudador.

- Determinación de las posibles deficiencias del sistema de control interno de la institución, con el objetivo principal de poder emitir recomendaciones para su mejora.

Para alcanzar estos objetivos, en el caso de la banca paralela son recomendables las siguientes técnicas:

\section{Realización de entrevistas}

Los objetivos de la entrevista en un caso de banca paralela son los siguientes:

1. Conseguir información sobre los hechos que han realizado el empleado, los clientes y/o los terceros afectados por el fraude. Es habitual, a partir de cierto volumen de transacciones, que el empleado lleve un registro "paralelo" de operaciones efectuadas, por lo que es necesario conocer dietarios, agendas, software y archivos informáticos que nos permitan conocer los clientes afectados y posibles colaboradores, y la duración del fraude. El área jurídica deberá asesorar sobre cómo realizar la recepción de la información y cómo manipularla (es recomendable la intervención y custodia notarial, a efectos de que estos documen- tos puedan ser utilizados como pruebas con posterioridad).

2. Confirmar o negar los hechos sobre la información que se ha obtenido hasta el momento.

3. Que el entrevistado admita los hechos y si es posible, indique las motivaciones. El conocimiento de la racionalización realizada por el empleado para llevar a cabo el fraude permitirá orientar la posible investigación posterior. Ante esta situación, habrá que valorar la comunicación a las autoridades competentes.

En el fraude de banca paralela, el efecto sorpresa en la entrevista es un factor a favor de la investigación que deberá manejarse, si es posible. La ignorancia de la investigación por parte del empleado puede permitir que tenga una actitud más abierta y no oriente la entrevista defensivamente.

La entrevista suele enfocarse usando las técnicas de interrogatorio policial y, en menor medida, las realizadas para obtener pruebas de auditoría (Rodríguez-Ramos \& Rodríguez-Ramos, 2012, pp. 19-21). Por ejemplo, se emplean las preguntas "zigzag" (sin relación entre ellas para obtener contradicciones por parte del entrevistado) y la técnica de "ponerse en los zapatos" (fabricar preguntas desde la perspectiva del empleado), principalmente.

Terminada la entrevista, la asesoría jurídica realiza un informe respecto a las manifestaciones y analiza la posible comisión de delitos públicos que se deban comunicar a las autoridades.

Adicionalmente, se deberán realizar entrevistas con todos aquellos empleados cercanos y relacionados - interna y externamente-con 
el empleado defraudador, y con los clientes identificados como perjudicados. Se intentará concluir sobre su posible conocimiento y/o participación en el fraude, para restituirles los fondos, si fuera procedente. Es una buena práctica solicitar a los posibles clientes perjudicados justificantes del origen de los fondos que entregaron al empleado defraudador y de los que no hay registro en la entidad.

Igualmente, si es posible, se deberán sostener entrevistas con clientes sospechosos de participar en el fraude, al ser receptores de fondos de manera irregular (operatoria de obtención de créditos fuera de los procedimientos del banco), para conocer su grado de conocimiento del fraude, cuantificar los fondos sustraídos y conocer su disposición a reconocer y regularizar la deuda con el banco.

Análisis de documentación

Si en las entrevistas se obtiene documentación de la contabilidad paralela, se deberá poner esta en relación con los posibles movimientos en los diarios contables del banco y con el perfil de la operatoria del cliente perjudicado, para verificar que el cliente ha sido objeto de fraude por parte del empleado.

El análisis de trazabilidad de fondos consiste en la identificación, si es posible, del destino que el empleado defraudador ha dado a los fondos. Así se podrán localizar los posibles perceptores y la finalidad aplicada. Los fondos pueden ser destinados al propio peculio del empleado defraudador o a terceras personas, negocios, sobornos, chantajes, etc.

Una vez conocido el fraude por clientes, personas de la zona de influencia territorial del empleado o la prensa, surgen "oportunistas" que pretenden estafar al banco, haciéndole creer que han sido perjudicados por el fraude. En estos casos, es necesario aplicar los procedimientos expuestos de justificación del origen de fondos y perfil operativo del cliente.

Investigación patrimonial y societaria del empleado defraudador, personas vinculadas y/o terceros

Los incrementos patrimoniales injustificados del empleado defraudador, personas vinculadas al mismo (familiares, amigos, etc.) y/o terceras personas identificadas pueden aclarar el destino de los fondos apropiados en la banca paralela. Igualmente, la participación de los sujetos indicados como accionistas y/o administradores en sociedades deben ser objeto de análisis con el mismo fin.

Consultas de comunicaciones, buscadores de internet y redes sociales

Las consultas de los instrumentos de comunicación corporativos (correos electrónicos, teléfonos y otros dispositivos, etc.), los buscadores y redes sociales pueden ofrecer datos importantes (dentro de la legalidad) para relacionar al empleado defraudador con personas y acciones implicadas en el fraude.

En la fase de planificación se habrá establecido un calendario y un objetivo de fecha de término de la investigación que deberá adaptarse a su avance y a los resultados obtenidos. Sin embargo, los equipos de investigación terminan proponiendo la finalización de la misma siguiendo un criterio de marginalidad, ya que llega un momento en que los recursos y el tiem- 
po necesarios para avanzar son muy superiores al resultado que se puede obtener. Se debe realizar una estimación del impacto cuantitativo de la parte que quedaría sin investigar y comunicarla a contabilidad para su tratamiento contable. Esta circunstancia debe ser descrita como una limitación al alcance de la investigación realizada en los informes que se redacten.

\section{d. Conclusiones: reporting, resultados y propuestas de mejora}

La comunicación de los resultados de la investigación debe realizarse periódicamente. La periodicidad viene definida por la importancia del fraude y los hechos que se vayan detectando.

Cada una de las comunicaciones debe ser revisada previamente por la asesoría jurídica de la institución y valorar las posibles acciones conforme los hechos se vayan poniendo de manifiesto. Asimismo, la asesoría jurídica debe valorar la actuación del equipo de investigación y los posibles riesgos legales, en su caso, en los que estén incurriendo (confidencialidad, obligación de poner documentación o hechos en conocimiento de las autoridades, etc.).

Finalizada la investigación, la elaboración del informe final y la comunicación de resultados deben realizarse por medios escritos. Con los resultados de la investigación, la alta dirección debe valorar tomar medidas concretas en relación con el fraude. Las más frecuentes son las siguientes:

- Reponer las cantidades defraudadas a los clientes que han sido perjudicados por el fraude $y$ no disponen de sus fondos en sus cuentas.

- Reclamar los fondos percibidos fraudulentamente a los clientes o terceros beneficiarios o, si procede, formalizar operaciones de crédito conforme a los procedimientos del banco.

- Adoptar medidas disciplinarias contra el empleado.

- Iniciar acciones legales, civiles o penales contra los defraudadores.

- Rescindir unilateralmente los contratos con clientes involucrados en el fraude de banca paralela conforme a las cláusulas de los mismos.

Por último, después de realizar el reporting interno y externo de la investigación, todos los niveles implicados y afectados del banco deben reflexionar respecto a los motivos de la comisión del fraude. El proceso de reflexión debe considerar:

- Fallos de control interno que han hecho posible el fraude.

- Posibles debilidades en los controles existentes.

- Grados de eficiencia de los protocolos existentes de comunicación de sospechas de fraude e investigación.

- Cumplimiento del código ético por las personas que rodeaban al empleado defraudador.

- Análisis de otros factores que han podido influir en el fraude (psicológicos, laborales, ausencia de políticas contra el fraude, transmisión de estas políticas, etc.).

Este proceso de reflexión debe igualmente ser documentado por escrito, informado a la alta dirección y acompañado de los planes de acción para mitigar la comisión de futuras bancas paralelas. La tabla 4 resume los aspectos más significativos del programa de investigación propuesto. 
PROPUESTA DE UN MOdELo PARA LA PREVENCIÓN / J. ARCENEGUI, J. MARTín, v. ObRERO / 653

\begin{tabular}{|c|c|}
\hline \multicolumn{2}{|c|}{ Programa de trabajo para la investigación del fraude por banca paralela } \\
\hline \multicolumn{2}{|c|}{ Protocolo de actuación } \\
\hline \multirow[t]{2}{*}{ 1. Evaluación preliminar } & Antecedentes del sospechoso \\
\hline & Razonabilidad de los indicios \\
\hline \multirow[t]{2}{*}{ 2. ¿Suspensión del empleado? } & Corte de operaciones paralelas \\
\hline & ¿Suspensión de colaboradores? \\
\hline \multirow[t]{2}{*}{ 3. Liderazgo y composición del equipo investigador } & Participación de terceros cualificados: informes \\
\hline & Equipos multidisciplinares \\
\hline 4. Personas que van a conocer la investigación & Línea jerárquica del defraudador, colaboradores, etc. \\
\hline \multicolumn{2}{|l|}{ 5. Definición de hitos y etapas } \\
\hline \multicolumn{2}{|l|}{ 6. Reporting intermedio y final } \\
\hline \multicolumn{2}{|c|}{ Planificación } \\
\hline
\end{tabular}

Objetivo clave: obtención de información

No aplicación del principio de la materialidad

Protección de la información relevante

Preparación de la entrevista con el sospechoso

Recopilación de información. Confidencialidad

No perjudicar futuras pruebas

Apoyo de la asesoría jurídica y otras áreas del banco

Evaluación jurídica de los delitos

Pruebas judiciales

Comunicación a autoridades

\section{Investigación}

Entrevistas

- Empleado sospechoso

- Empleados cercanos

- Clientes perjudicados

- Colaboradores y clientes beneficiados

Análisis de la información

La trazabilidad de los fondos defraudados
Obtención de información. Recepción y manipulación

Autoría y motivación

Confirmación de los hechos

Técnicas policiales

Justificantes de operaciones fraudulentas

Disposición a reconocer y regularizar deudas

Contraste con datos internos

Trazabilidad de los fondos

El problema de los "oportunistas"

Origen

- Saldos en abandono

- Depósitos sustraídos a clientes

- Préstamos concedidos irregularmente

Destino

- Patrimonio del defraudador o vinculados 


\begin{tabular}{|c|c|}
\hline \multicolumn{2}{|c|}{ Programa de trabajo para la investigación del fraude por banca paralela } \\
\hline \multicolumn{2}{|c|}{ Protocolo de actuación } \\
\hline & - Soborno, extorsión \\
\hline & - Lavado de dinero, evasión fiscal, etc. \\
\hline Investigación patrimonial y societaria & Accionistas, administradores, testaferros \\
\hline \multirow[t]{3}{*}{ Comunicaciones } & Correos y llamadas corporativas \\
\hline & Internet \\
\hline & Redes sociales \\
\hline \multicolumn{2}{|c|}{ Conclusiones: reporting, resultados y propuesta de mejora } \\
\hline \multirow[t]{3}{*}{ Reporting y documentación } & Periodicidad \\
\hline & Valoración de la asesoría jurídica \\
\hline & Informe final \\
\hline Comunicación de resultados a la alta dirección & Reponer las cantidades sustraídas \\
\hline \multirow[t]{4}{*}{ y propuesta de acciones } & Reclamar a los beneficiados \\
\hline & Medidas disciplinarias \\
\hline & Acciones legales \\
\hline & Rescisión de contratos de clientes \\
\hline \multirow[t]{4}{*}{ Reflexión final - Propuestas de mejora } & Fallos y debilidades en los controles \\
\hline & Eficacia de los canales de denuncias \\
\hline & Cumplimiento código ético \\
\hline & Información de mejoras a la alta dirección \\
\hline
\end{tabular}

Tabla 4

Programa de trabajo para la investigación del fraude por banca paralela

Fuente: elaboración propia

\section{Conclusiones}

La naturaleza de las actividades que desarrollan las entidades financieras propicia la aparición de casos de fraude y expone a los bancos a la realización de estafas. Los delitos y actos desleales por parte de los empleados del sector bancario provocan importantes pérdidas anuales a los bancos para los que trabajan y a sus clientes. Además, hay una estrecha relación entre fraude y crisis económica. Por ello, en España, la crisis económica y la debilidad del sector financiero no han favorecido la mitigación del fraude bancario.
En el fraude por banca paralela, normalmente, un empleado realiza la actividad bancaria pero al margen del banco, aprovechando la oportunidad que su puesto de trabajo le proporciona, sin que quede registro de ella en la contabilidad de la institución financiera y le da apariencia de legalidad, al manipular registros y documentación.

Uno de los factores que dificultan el estudio y la lucha contra las bancas paralelas es la confidencialidad que suele rodearla. Las entidades financieras no suelen hacer públicos los casos que sufren, dado que su negocio se basa en 
su reputación y en la confianza de sus clientes. La escasez de estudios y estadísticas de fraude por banca paralela con profundidad histórica dificulta la mitigación del riesgo y hace que los casos publicados por los medios de comunicación sean prácticamente la única fuente de información externa de las propias entidades financieras.

Hay unas características habituales en las bancas paralelas conocidas: el fraude es progresivo e incremental con solapamiento de clientes y operaciones; el empleado desleal entrega a clientes contratos y extractos bancarios simulados; es un fraude prolongado y requiere un esfuerzo considerable por parte del defraudador. Entre los motivos de su comisión están el prestigio personal, trato de favor, participación en negocios con conflicto de interés, etc. La deficiente identificación de riesgos y/o vigilancia de las operaciones y personas es otra de sus principales causas.

Para desarrollar una banca paralela es necesario realizar varios tipos de fraudes a la vez. Es un megafraude que suele implicar estafa y apropiación indebida, falsedad documental, corrupción, evasión fiscal y lavado de dinero, principalmente.

El empleado desleal suele poseer una elevada formación técnico-profesional, buen conocimiento de los sistemas de control del banco, cierta edad y antigüedad laboral, y acceso a tecnología avanzada para falsificar documentación física o electrónica. A estas características hay que añadir un escaso nivel ético o moral que le permite racionalizar un fraude prolongado con múltiples estafados. Además del defraudador, intervienen desde clientes estafados no cooperantes hasta colaboradores y cómplices. Adicionalmente, los compañeros y jefes del defraudador pueden colaborar pasivamente al no comunicar los indicios que perciban del fraude.

Hay un elevado consenso entre las principales instituciones auditoras en el esquema que debe seguir la prevención del riesgo de fraude: la elaboración de un programa de gestión del fraude, la evaluación del riesgo y las medidas de mitigación. Unas de las principales aportaciones de este trabajo son la identificación del riesgo inherente, la determinación de los indicadores de riesgo y la implantación de los controles básicos para el riesgo de fraude por banca paralela. Dadas las características del fraude descritas, los controles propuestos tienen su fundamentación en el principio de segregación de funciones.

Los códigos éticos son necesarios como medida de mitigación, pero deben ser más explícitos con aquellos fraudes, como el de la banca paralela, que tienen un elevado impacto económico, legal y reputacional. Los bancos deben hacer un esfuerzo mayor para que sus empleados conozcan y asuman las normas éticas. Igualmente, debe considerarse la correcta comunicación de los casos de banca paralela detectados y las consecuencias para clientes, empleados desleales y el propio banco. Por último, la incentivación del cumplimiento del código es adecuada, pero los incumplimientos - como la banca paralela-deben estar acompañados de medidas punitivas ejemplares.

Una vez detectados indicios de fraude, el banco debe acometer la investigación forense para responder las tradicionales preguntas qué, cómo, por qué, quién y cuándo. El banco 
debe activar el protocolo de actuación que comprende, entre otras actuaciones, la formación de equipos multidisciplinares, frecuentemente la participación de terceros independientes, la suspensión de los empleados sospechosos y sus posibles colaboradores, etc.

Durante la planificación de la investigación, el objetivo clave es la obtención de información oculta. Por ello se debe actuar confidencialmente y, con el apoyo de la asesoría jurídica, extremar la atención para no perjudicar las futuras pruebas y valorar los posibles delitos cometidos para comunicarlos a las autoridades.

Siempre que sea posible, la investigación debe utilizar la entrevista personal con los sospechosos y el resto de intervinientes, el análisis de la información para conocer el origen y destino de los fondos ocultos, la investigación societaria y patrimonial del sospechoso, y el análisis legal de las comunicaciones.

Por último, se deben documentar y comunicar los resultados a la alta dirección y a las autoridades, y proponer las acciones de reposición a terceros que correspondan, las acciones legales y laborales correspondientes y la rescisión de los contratos de clientes colaboradores si los hubiera.

El presente trabajo ha sido elaborado como modelo de referencia para ser usado fundamentalmente por entidades financieras y autoridades en España, dado que las características descritas corresponden a fraudes cometidos en este país. No obstante, es posible su aplicación, total o parcial, en otros entornos geográficos dependiendo de los procedimientos bancarios utilizados y la legislación aplicable.

Las futuras líneas de investigación de este tipo de fraude deberían desarrollarse mediante el análisis de los eventos de pérdidas por bancas paralelas recogidos en las bases de datos institucionales de riesgo operacional creadas recientemente.

El principal problema en la lucha contra el fraude por banca paralela es la escasez de información sobre esta práctica. La discreción de los bancos se vuelve muy perjudicial cuando la información del fraude llega parcialmente a los empleados y clientes por los medios de comunicación. En este sentido, los supervisores pueden encontrar el equilibrio entre la confidencialidad necesaria y la adecuada transparencia, lo que obligaría a las entidades a comunicar los fraudes sufridos y elaboraría memorias anuales de fraude (similares a las de reclamaciones elaboradas por el Banco de España o la Comisión Nacional del Mercado de Valores, CNMV) con datos agregados de entidades.

\section{Referencias}

American Institute of Certified Public Accountants, AICPA (2002). AU Section 316. Consideration of Fraud in a Financial Statement Audit. Disponible en: http://www. aicpa.org/Research/Standards/AuditAttest/ DownloadableDocuments/AU-00316.pdf Ansótegui, Carmen; Gómez-Bezares, Fernando \& González-Fabre, Raúl (2014). Ética de las finanzas. Bilbao: Editorial Desclée.

Arredondo-Trapero, Florina Guadalupe; GarzaGarcía, Jorge de la \& Vázquez-Parra, José Carlos (2014). Transparencia en las organizaciones, una aproximación desde la perspectiva de los colaboradores. Estudios Gerenciales, 30 (133), 408-418. Disponi- 
ble en: http://www.redalyc.org/articulo. oa?id=21232399009

Arredondo-Trapero, Florina Guadalupe; GarzaGarcía, Jorge de la \& Villa-Castaño, Lida E. (2014). Propuestas para el diseño de un código de ética empresarial basado en la ética kantiana. Cuadernos de Administración, 30 (52), 9-19. Disponible en: http://www. redalyc.org/articulo.oa?id=225033236002, http://cuadernosdeadministracion.univalle. edu.co/index.php/cuadernosadmin/article/ view/2832/3041

Badillo-Ayala, Jorge (2008). Auditoría forense / Más que una especialidad profesional, una misión: prevenir y detectar el fraude financiero. Quito, Ecuador. Disponible en: https:// na.theiia.org/translations/PublicDocuments/ Auditoria_Forense_Una_Misi\%C3\%B3n_ JBadillo_Mayo08(14023).pdf

Banco de Desarrollo Empresarial, Bancoldex (2015). Programa de prevención de riesgos de fraude y corrupción. Documento Bancoldex. Versión 4. Disponible en: http://www. bancoldex.com/documentos/4667_ Programa_de_prevencion_riesgos_de_ fraude_y_corrupcion.pdf

Banco de España (2004). Circular 4/2004 de 22 de diciembre. Entidades de crédito. Normas de información financiera pública y reservada, y modelos de estados financieros. Actualizada a 17 de agosto de 2015. Disponible en: http:// www.bde.es/f/webbde/SJU/normativa/ circulares/4.2004.pdf

Banco de España (2015a). Cuentas financieras de la economía española 1995-2014. SEC 2010. Series trimestrales y anuales. Madrid: Banco de España. Disponible en: http://
www.bde.es/f/webbde/SES/Secciones/ Publicaciones/PublicacionesAnuales/ CuentasFinancierasEconomia/14/Fich/ cfee14.pdf

Banco de España (2015b). Boletín Estadístico. Disponible en: http://www.bde.es/webbde/ es/estadis/infoest/bolest4.html

Banco de España, Dirección General de Supervisión (2012). Guía para la elaboración de la matriz de riesgos. Madrid: Banco de España. Disponible en: http://www. bde.es/f/webbde/INF/MenuVertical/ Supervision/transparencia/ficheros/Guia_ para_la_elaboracion_de_la_matriz_de_ riesgos_ESP.PDF

Baracaldo-Lozano, Natalia Andrea (2013). Diagnóstico de gobierno corporativo como mecanismo en la prevención del fraude en empresas familiares (Aplicación de método de casos). Cuadernos de Contabilidad, 14 (35), 581-615. Disponible en: http:// revistas.javeriana.edu.co/index.php/ cuacont/article/viewFile/7108/5630

Berzosa, Carlos (2013). La difícil relación entre ética y economía. Revista de Economía Mundial, 35, 271-284. Disponible en: http://rabida.uhu.es/dspace/bitstream/ handle/10272/7711/La_dificil_\%20 relacion_entre_etica_y_economia. pdf? sequence $=2$

Comité de Supervisión Bancaria de Basilea, Bank for International Settlements, BIS (2006). Convergencia internacional de medidas y normas de capital. Marco revisado, versión integral. Basilea, Suiza: Bank for International Settlements, BIS. Disponible en: http://www.bis.org/publ/bcbs128_es.pdf 
Comité de Supervisión Bancaria de Basilea, Bank for International Settlements, BIS (2011). Principles for the Sound Management of Operational Risk. Basilea, Suiza: Bank for International Settlements, BIS. Disponible en: http://www.bis.org/publ/bcbs195.pdf

Committee of Sponsoring Organizations of the Treadway Commission, COSO (2013). Control Interno - Marco Integrado.

Cressey, Donald R. (1961). The Prison: Studies in Institutional Organization and Change. New York: Holt, Rinehart \& Winston.

Fernández-Sanguino Fernández, Julio (2000). El fraude interno en la empresa: especial referencia a las entidades de crédito. Tesis doctoral. Universidad Nacional de Educación a Distancia, UNED. Madrid. España.

Fernández-Sanguino Fernández, Julio (2002). Fraudes e irregularidades en la actividad financiera. X Conferencia anual de Ética, Economía y Dirección, 13 y 14 de junio de 2002 - Universidad Pontificia Comillas. Papeles de Ética, Economía y Dirección, 7, 99108. Disponible en: http://www.eticaed.org/ fdez-sanguino.pdf

Francis, Louis (2010). Banking on Robbery: The Role of Fraud in the Financial Crisis. Casualty Actuarial Society E-Forum, 2, 1-54. Disponible en: https://www.casact.org/ pubs/forum/10fforumpt2/Francis.pdf

Freixas, Xavier \& Rochet, Jean Charles (1999).

Economía bancaria. Barcelona: Editorial Antoni Bosch.

Galvis-Castañeda, Iván Eduardo (2008). Análisis conductual forense en un caso de delito financiero. Cuadernos de Contabilidad, 9 (25), 465-486. Disponible en: http:// cuadernosdecontabilidad.javeriana.edu.co/ vol9_n_25/vol9_25_3.pdf

Girgenti, Richard H. \& Hedley, Timothy P. (2013). Gestión del riesgo de fraude e irregularidades empresariales: [los retos en un entorno global, regulado y digital]. Madrid: McGraw-Hill.

Godfrey, Paul C.; Merrill, Craig B. \& Hansen, Jared M. (2009). The Relationship between Corporate Social Responsibility and Shareholder Value: An Empirical Test of the Risk Management Hypothesis. Strategic Management Journal, 30 (4), 425-445.

González-Esteban, Elsa \& García-Marzá, Domingo (2006). La responsabilidad social empresarial (RSE) en Europa: la apuesta por un nuevo modelo de empresa. Una revisión crítica desde la ética empresarial. Revista de Pensament i Analisi, 6, 157-172. Disponible en: http://www.raco.cat/index.php/RecercaPensamentAnalisi/article/view/106988

Hartman, Laura P.; Desjardins, Joe \& Espinoza, Francisco A. (2011). Ética en los negocios. Decisiones éticas para la responsabilidad social e integridad personal. México: McGraw-Hill.

Ibarra-Ramos, Ramón (2002). Código de ética, cómo implementarlo en la empresa. México: Editorial Trillas.

Institute of Internal Auditors (IIA), American Institute of Certified Public Accountants (AICPA) \& Association of Certified Fraud Examiners (ACFE) (2008). Managing the Business Risk of Fraud: A Practical Guide. Disponible en: https://www.acfe.com/ uploadedfiles/acfe_website/content/ documents/managing-business-risk.pdf 
Instituto de Auditores Internos de España, IAI (2013). Definición e implantación de apetito de riesgo. Colección La fábrica del pensamiento. Buenas prácticas en gestión de riesgos. Madrid: Instituto de Auditores Internos de España, IAI. Disponible en: http://auditoresinternos.es/uploads/media_ items/apetito-de-riesgo-libro.original.pdf

Instituto de Auditores Internos de España, IAI (2015). Manual de gestión de riesgo de fraude: prevención, detección e investigación. Colección La fábrica del pensamiento. Buenas prácticas en gestión de riesgos. Madrid: Instituto de Auditores Internos de España, IAI. Disponible en: http:// auditoresinternos.es/uploads/media_items/ f\%C3\%A1brica-fraude.original.pdf International Accounting Standards Board, IASB (2012). Resumen técnico NIC 37 provisiones, pasivos contingentes y activos contingentes. Londres: International Accounting Standards Board, IASB. Disponible en: http://www.ifrs.org/IFRSs/Documents/ Spanish\%20IAS\%20and\%20IFRSs\%20 PDFs\%202012/IAS\%2037.pdf

KPMG, Equipo de KPMG Forensic en España (2013). Perfiles globales del defraudador. Presente y futuro de los delitos económicos. Madrid: KPMG. Disponible en: www. kpmg.com/fraudster, http://www.kpmg. com/ES/es/ActualidadyNovedades/ ArticulosyPublicaciones/Documents/ Perfiles-globales-defraudador.pdf

Levi, Michael \& Smith, Russell G. (2011). Fraud Vulnerabilities and the Global Financial Crisis. Trends \& Issues in Crime and Criminal Justice, Australian Institute of Criminology, 422, 1-5.
Disponible en: http://www.aic.gov.au/media_ library/publications/tandi_pdf/tandi422.pdf López-Rubiano, José Armando \& Mora-Pedraza, Elsa Milena (2006). Manual de auditoría forense para las entidades bancarias en Colombia. Bogotá: Universidad de San Buenaventura, Facultad de Ciencias Empresariales, Contaduría Pública. Disponible en: http://www.biblioteca.usbbog.edu.co:8080/ Biblioteca/BDigital/37933.pdf

Molina-Sánchez, Horacio D. (2014). El fraude en la información empresarial en el marco de las relaciones financieras. Revista de Fomento Social, 69, 395-420. Disponible en: http:/www.revistadefomentosocial.es/ index.php/todos-los-documentos/276/3138276a1/download

Muñoz-Martín, Juan (2013). Ética empresarial, responsabilidad social corporativa (RSC) y creación de valor compartido (CVC). Journal Globalization, Competitiveness \& Gobernability, GCG, Georgetown University, 7 (3), 76-88. Disponible en: https:// gcg.universia.net/article/view/457/ etica-empresarial-responsabilidadsocial-corporativa-rsc-creacion-valorcompartido-cvc-

Panamá (1998). Decreto ley 9 del 26 de febrero de 1998, por el cual se reforma el régimen bancario y se crea la Superintendencia de Bancos. Gaceta Oficial, 23.499, 12 de marzo de 1998. Disponible en: http://panama. justia.com/federales/decretos-leyes/9-de1998-mar-12-1998/gdoc/

Perú (2015). Ley 26702, texto concordado de la Ley general del sistema financiero y del sistema de seguros y orgánica 
de la Superintendencia de Banca y

Seguros. Disponible en: http://www.

cmactacna.com.pe/documentos/

transparencia/ProteccionAlUsuario/01\%20

-Ley_26702_\%20LEY\%20GENERAL\%20

DEL\%20SISTEMA\%20FINANCIERO.pdf

Pina-Barrajón, Nuria (2012). Posición de la entidad bancaria respecto del delito de falsedad en documento en concurso con la estafa. Seminario Permanente de Ciencias Sociales, SPCS Documento de trabajo 2012/6. Cuenca, España: Universidad de Castilla-La Mancha, Facultad de Ciencias Sociales. Disponible en: https:/www.uclm.es/CU/csociales/pdf/ documentosTrabajo/2012/6.pdf

PricewaterhouseCoopers Consultores, Auditores y Compañía Limitada, PwC (2009). Fraude en tiempos de crisis. Un análisis sobre cómo el fraude y otros riesgos de integridad afectarán el negocio en el año 2009. Santiago de Chile: PricewaterhouseCoopers, PwC Chile. Disponible en: https://www.pwc.com/cl/es/ publicaciones/assets/fraude-tiempo-crisis.pdf

PricewaterhouseCoopers, PwC (2015). Encuesta sobre fraude y delito económico 2014. Resultados en España. Madrid: PricewaterhouseCoopers. Disponible en: www.pwc. com/crimesurvey, http://www.pwc.es/es/ publicaciones/gestion-empresarial/assets/ encuesta-fraude-economico-2014.pdf

Ramírez-Moncada, Nicolás Darío (2008). El fraude en la actividad bancaria. El Cuaderno - Escuela de Ciencias Estratégicas, 2 (4), 279296. Disponible en: https://dialnet.unirioja. es/descarga/articulo/2991253.pdf

Rodríguez, María del Pilar \& Díaz, Andrés Felipe (2004). Códigos éticos: construcción co- lectiva del carácter organizacional. El caso de la Universidad Nacional de Colombia, sede Manizales. Innovar, Revista de Ciencias Administrativas y Sociales, 24 (28), 3958. Disponible en: http://www.redalyc.org/ pdf/818/81802404.pdf

Rodríguez-Gutiérrez, Pablo; Fuentes-García, Fernando J. \& Sánchez-Cañizares, Sandra María (2013). Transparency in Social Disclosure in Financial Institutions through Spanish CSR Reports in the Context of Crisis. Universia Business Review, UBR, 38, 84107. Disponible en: https://ubr.universia. net/article/viewFile/882/1008

Rodríguez-Ramos, Luis \& Rodríguez-Ramos, Gabriel (prólogo). En Julio García-Ramírez, Luis Romero \& Florentino García (2012). La técnica del interrogatorio. Madrid: Editorial Rasche. Rodríguez-Zarco, Juan Manuel (1991). Manual de prevención del fraude. Madrid: Esabe Editorial. Sen, Amartya (1989). Sobre ética y economía. Madrid: Alianza Editorial.

- Fecha de recepción: 24 de agosto de 2015

- Fecha de aceptación: 27 de octubre de 2015

- Disponibilidad en línea: 15 de mayo de 2016

\section{Para citar este artículo}

Arcenegui-Rodrigo, J. A.; Martín-Lozano, J. M. \& Obrero-Castilla, V. (2015). Propuesta de un modelo para la prevención y gestión del riesgo de fraude interno por banca paralela en los bancos españoles. Cuadernos de Contabilidad, 16(42), 625660. http://dx.doi.org/10.11144/Javeriana. cc16-42.pmpg 